Supporting Information for:

\title{
Nickel-Mediated Dehydrogenative Aryl-Aryl Homocoupling of a Bulky Phosphino-Pyridine
}

\author{
Vennela Mannava, Kate A. Jesse, John S. Anderson \\ Department of Chemistry, The University of Chicago, Chicago, Illinois 60637, United States \\ Correspondence to: jsanderson@uchicago.edu
}


Table of Contents

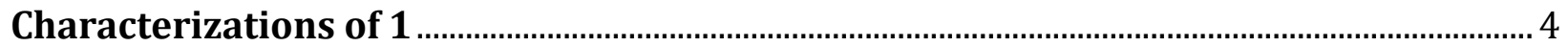

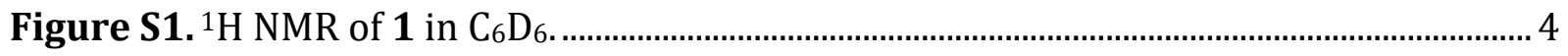

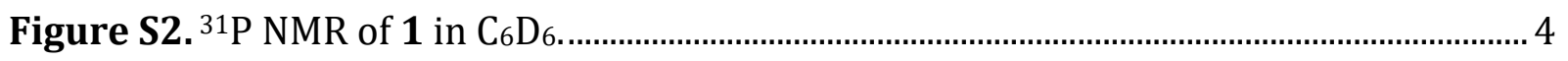

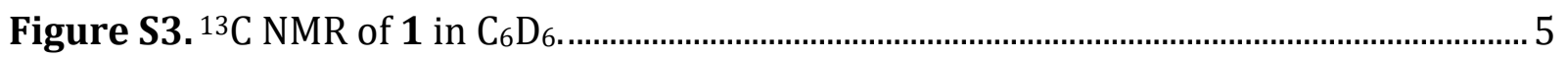

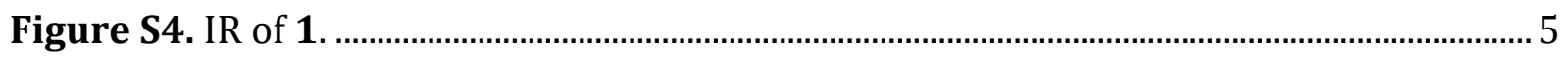

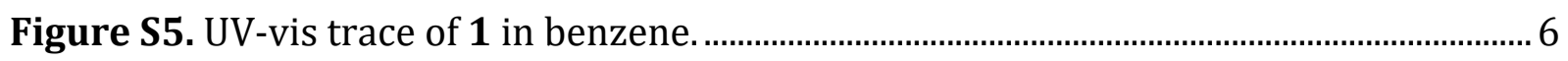

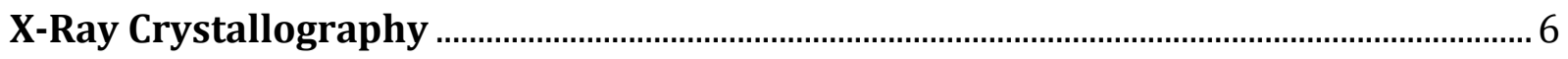

Experiment Description ............................................................................................. 6

Table S1. Crystallographic data for 1. …………………………………………………...

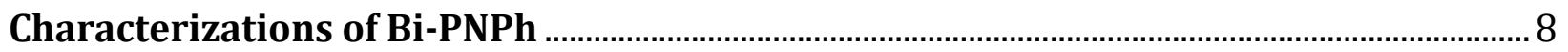

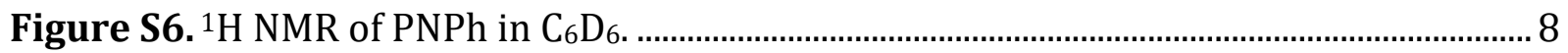

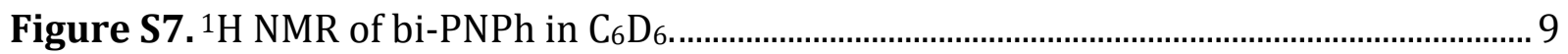

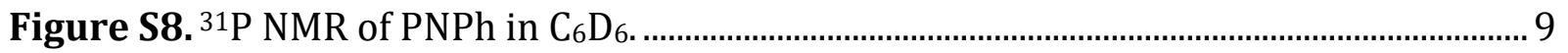

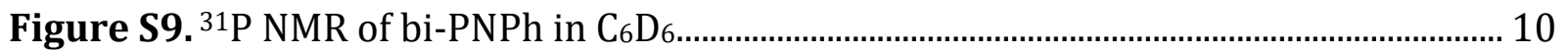

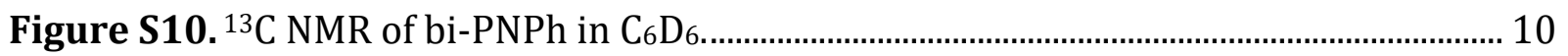

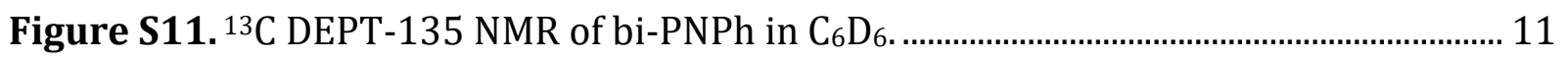

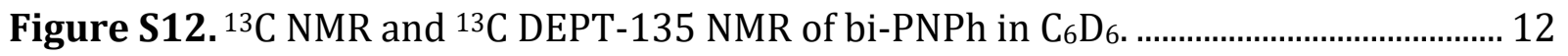

Figure S13. Sequential ${ }^{31} \mathrm{P}$ NMR of sealed thermolysis of $\mathbf{1}$ in toluene................................. 12

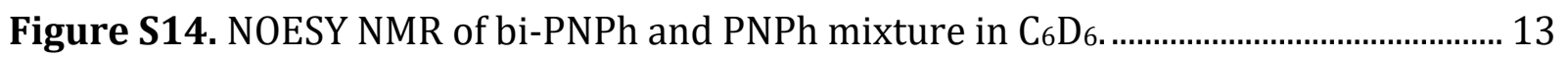

Figure S15. MS data from ESI-MS analysis of bi-PNPh and PNPh mixture + AgOTf. ......... 13

Pulsed Gradient Spin-Echo NMR …………………………………………………………....... 14

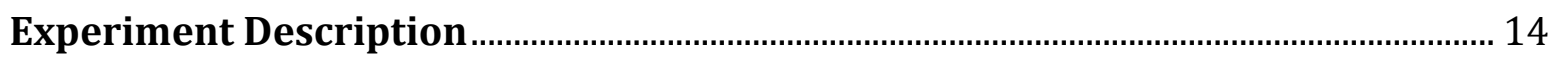

Figure S16. Signal decay of PNPh peak (left) and bi-PNPh peak (right) in $\mathrm{C}_{6} \mathrm{D}_{6} \ldots \ldots \ldots . . . .15$

Figure S17. Stejskal Tanner Plot of bi-PNPh and PNPh data................................................ 15

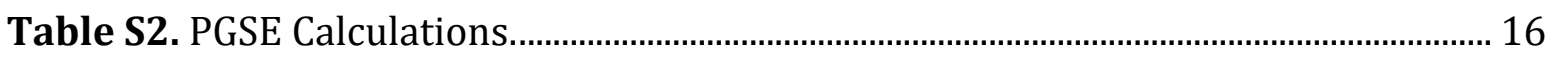

Identification of Volatile Final Products .................................................................................. 17

Figure S18. Sequential ${ }^{1} \mathrm{H}$ NMR of sealed long-term $\mathrm{Ni}(\mathrm{COD})_{2}+\mathrm{PNPh}$ reaction in

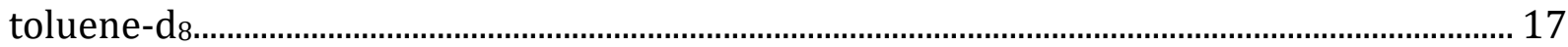

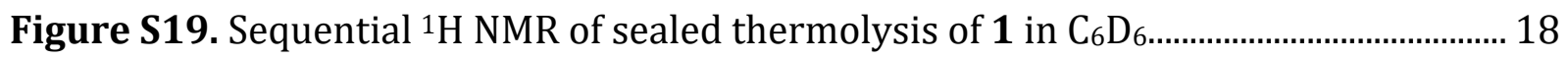

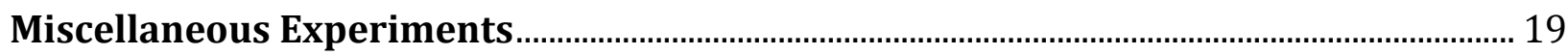

Figure S20. Sequential ${ }^{1} \mathrm{H}$ NMR of sealed long-term $\mathrm{Ni}(\mathrm{COD})_{2}+\mathrm{PNPh}$ reaction with 1-

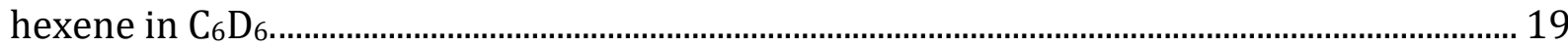

Figure S21. MS data of 2- and 3-hexene from GC-MS analysis of long-term $\mathrm{Ni}(\mathrm{COD})_{2}+$ PNPh reaction with 1-hexene.......................................................................................................... 19

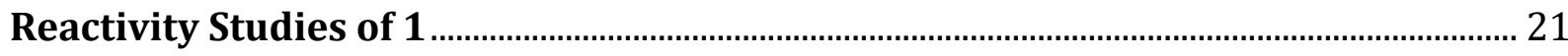


Table S3. Summary of reactivity studies of 1................................................................... 21

Figure S22. Sequential ${ }^{1} \mathrm{H}$ NMR of $\mathbf{1}+$ MeI reaction in $\mathrm{C}_{6} \mathrm{D}_{6}$ (partial spectra)............... 22

Figure S23. MS data from ESI-MS analysis of 1 + MeI reaction products........................ 23

Figure S24. ${ }^{1} \mathrm{H}$ NMR of $\mathbf{1}+$ MeI reaction mixture in $\mathrm{C}_{6} \mathrm{D}_{6}$ after filtration........................ 24

Figure S25. ${ }^{31} \mathrm{P}$ NMR of $\mathbf{1}+$ MeI reaction mixture in $\mathrm{C}_{6} \mathrm{D}_{6}$ after filtration........................ 24

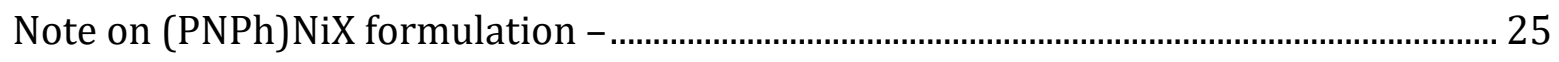

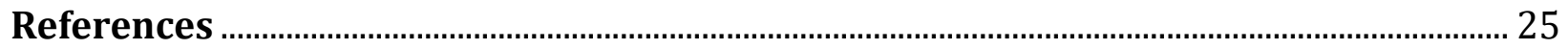




\section{Characterizations of 1}

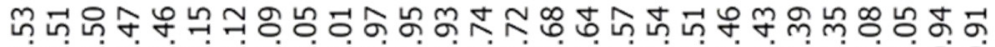

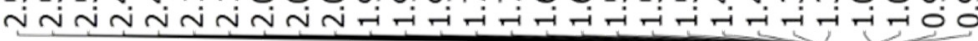<smiles></smiles>

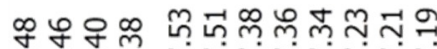

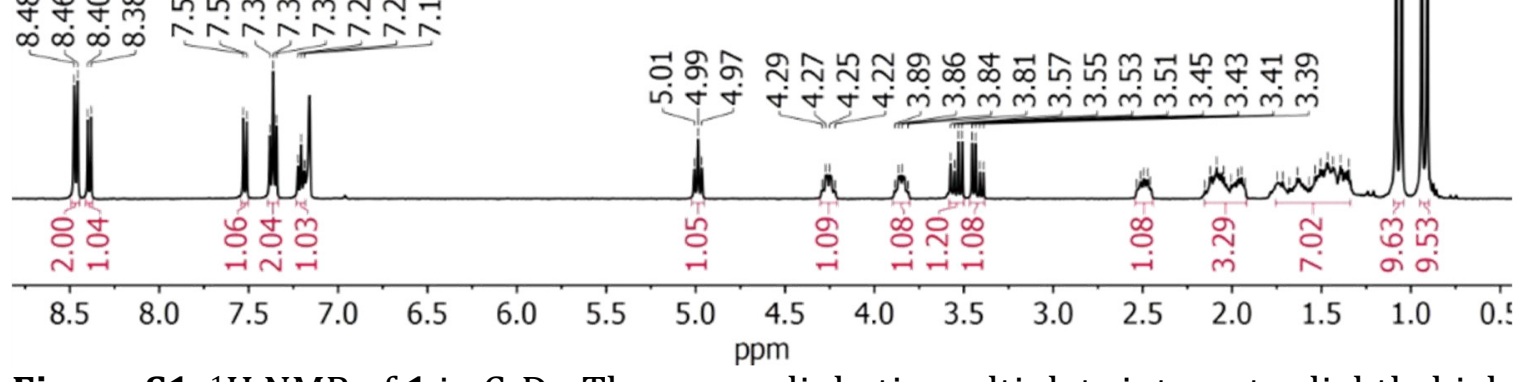

Figure S1. ${ }^{1} \mathrm{H}$ NMR of 1 in $\mathrm{C}_{6} \mathrm{D}_{6}$. The many aliphatic multiplets integrate slightly higher than the expected 10 protons, likely due to minor solvent impurity.

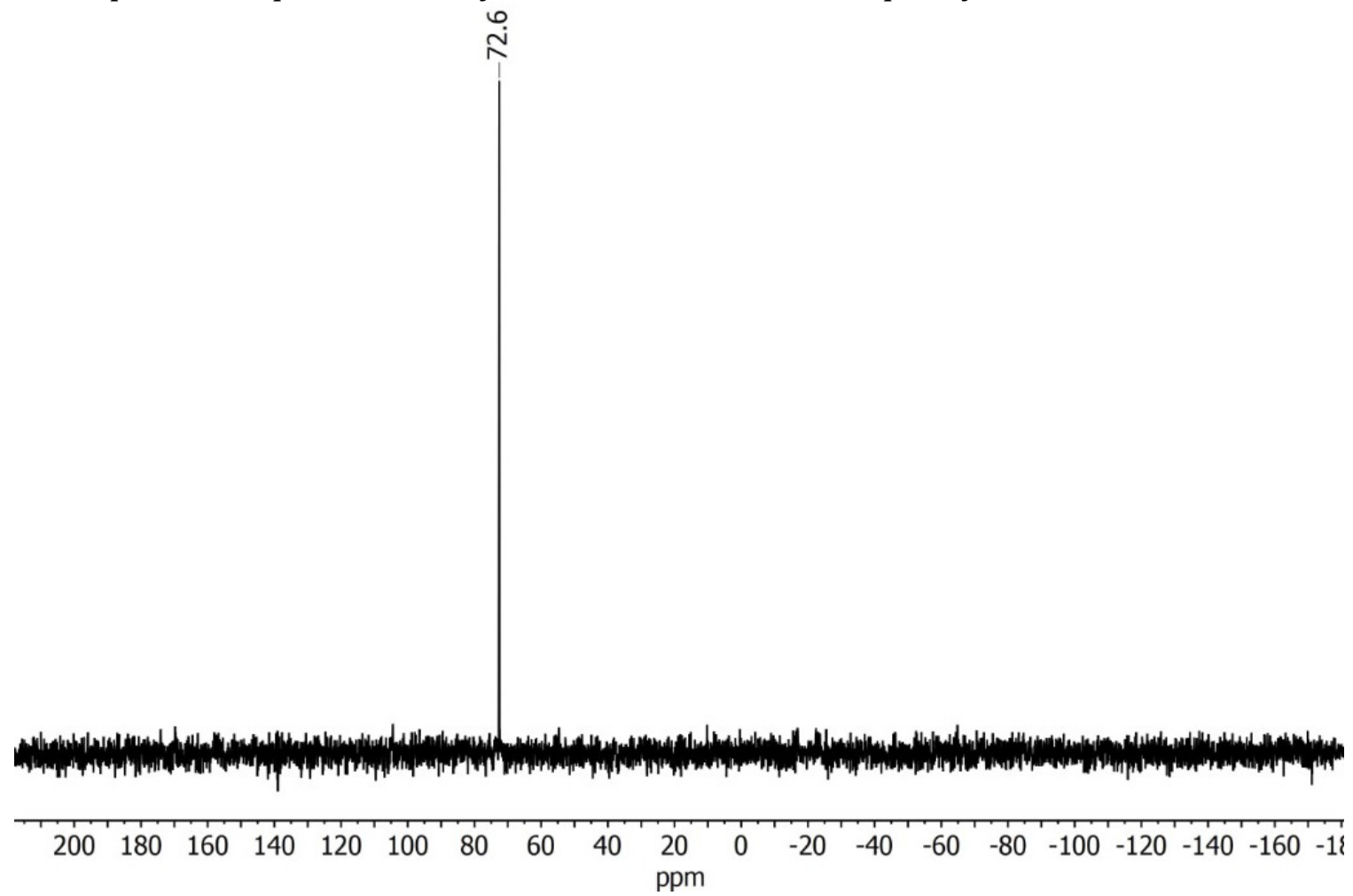

Figure S2. ${ }^{31} \mathrm{P}$ NMR of 1 in $\mathrm{C}_{6} \mathrm{D}_{6}$. 


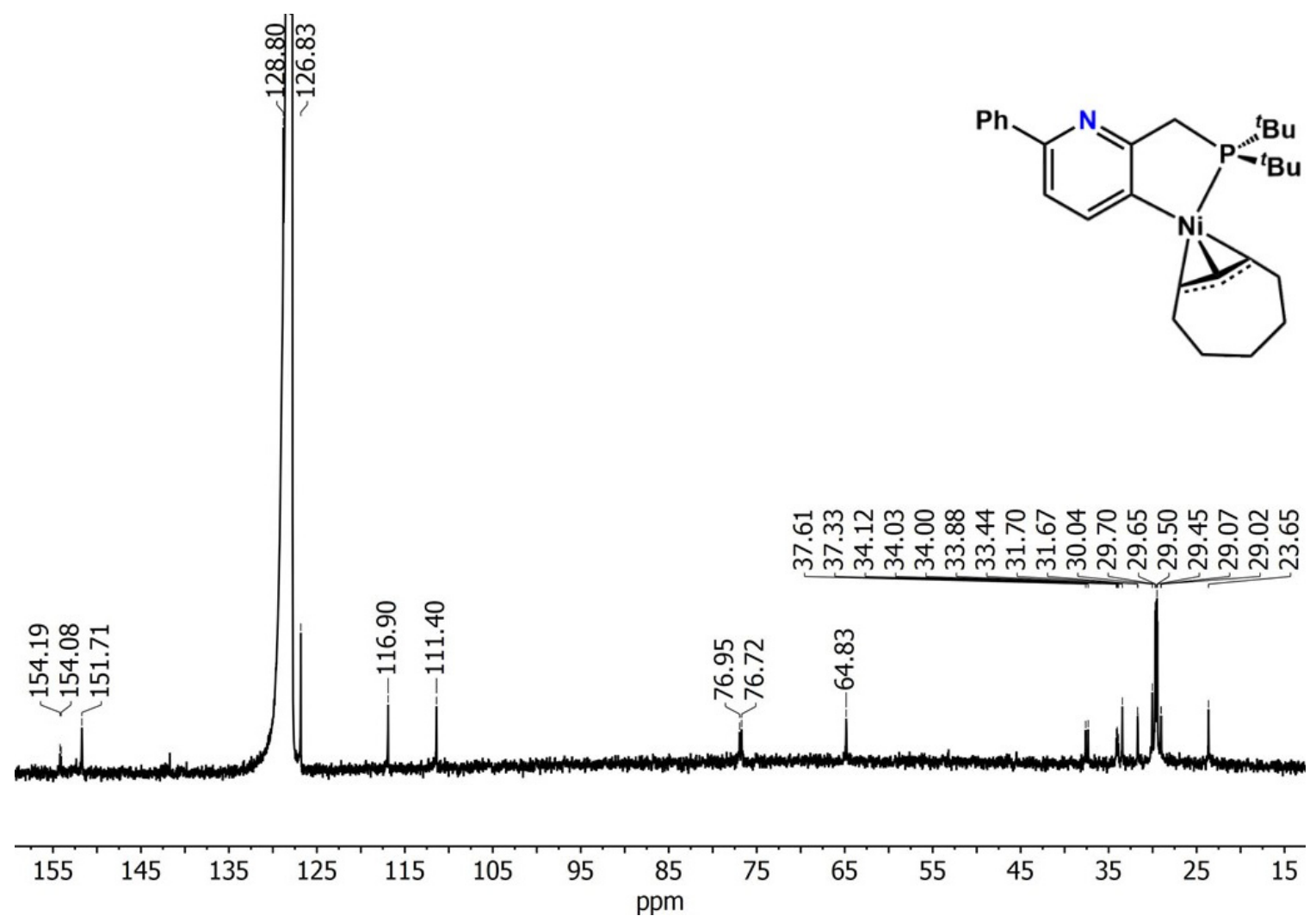

Figure S3. ${ }^{13} \mathrm{C}$ NMR of 1 in $\mathrm{C}_{6} \mathrm{D}_{6}$.

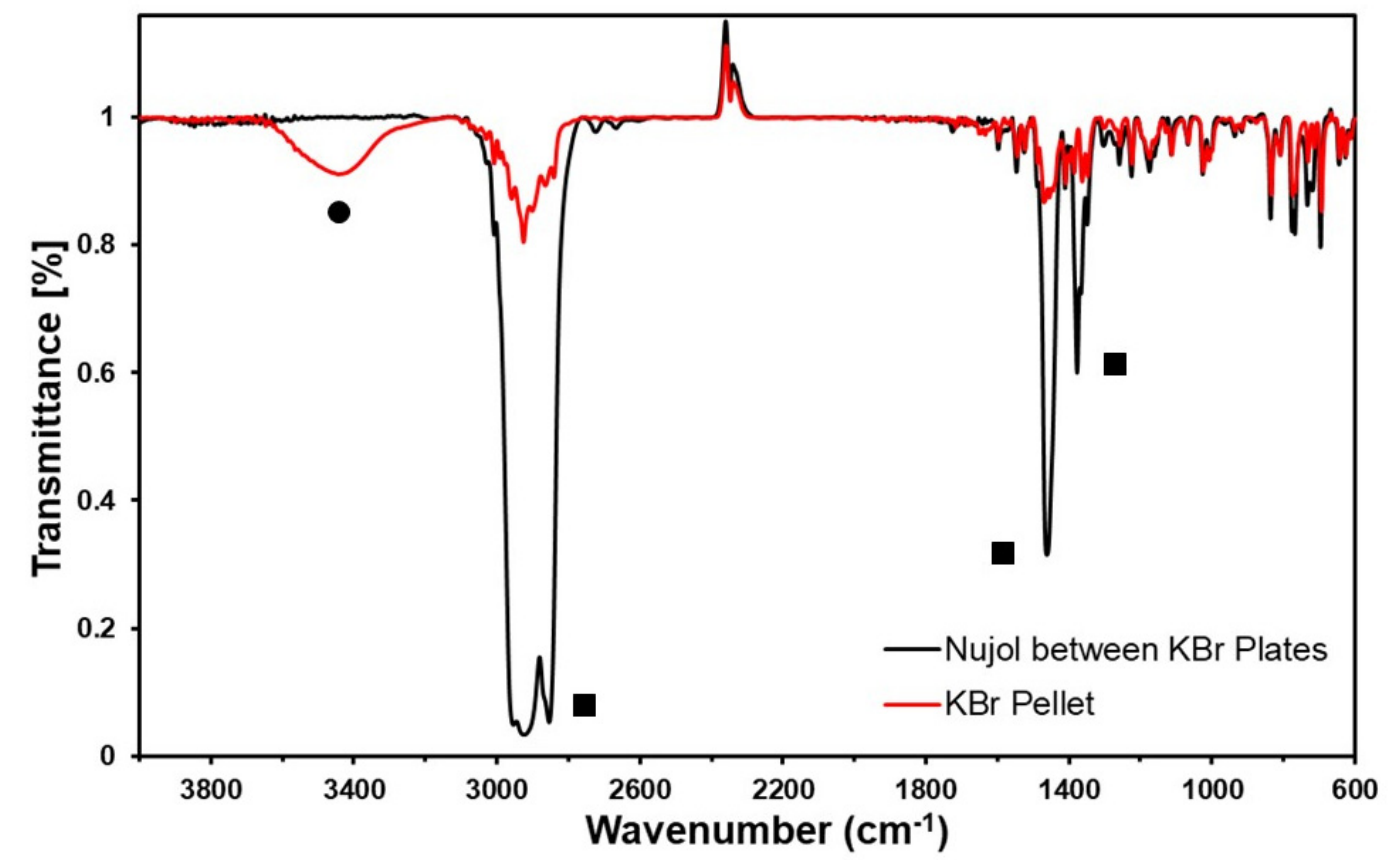

Figure S4. IR of $\mathbf{1}$. The $\mathrm{KBr}$ powder used to make the pellet has water contamination, indicated by a circle. The Nujol peaks are indicated by squares. 


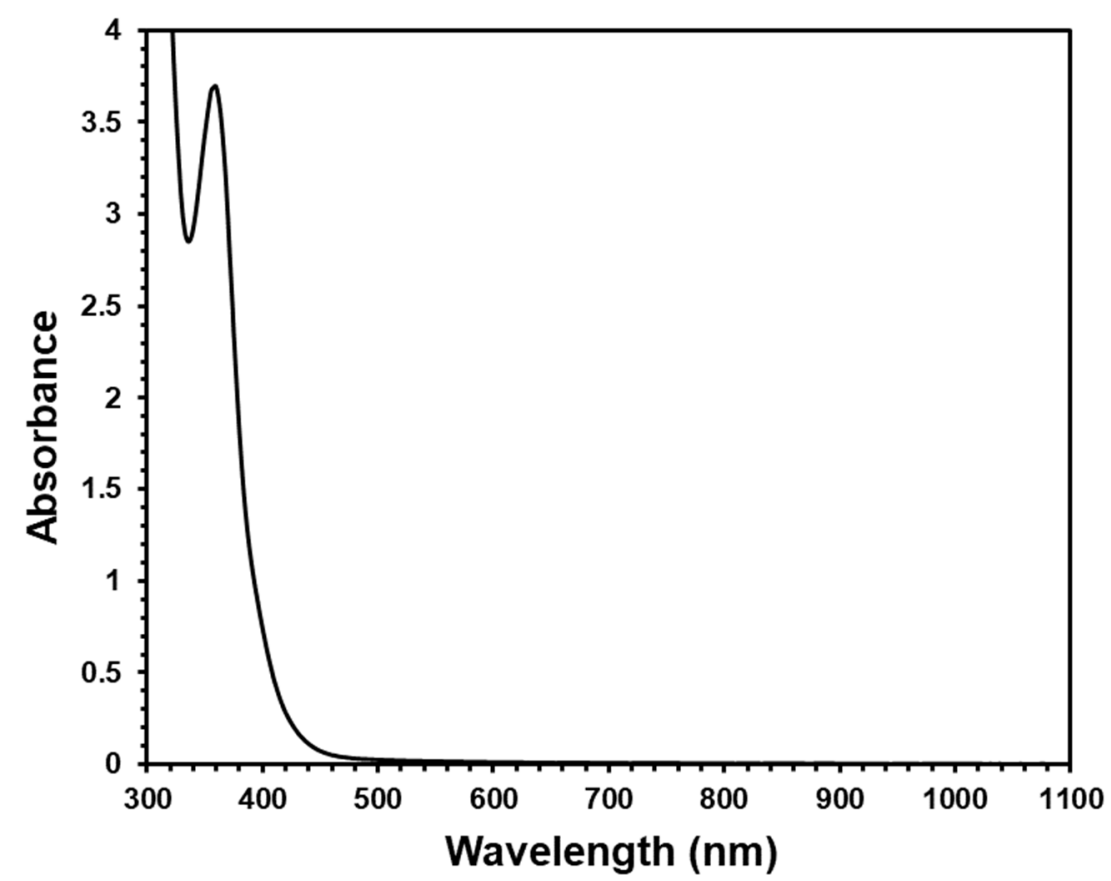

Figure S5. UV-vis trace of $\mathbf{1}$ in benzene.

\section{X-Ray Crystallography}

\section{Experiment Description}

The single crystal of complex 1 (CCDC 1908839) was mounted on a cryo-loop and transferred into the cold nitrogen stream of a Bruker D8 Venture diffractometer. The diffraction data were measured at $100 \mathrm{~K}$ on a Bruker D8 VENTURE diffractometer equipped with a microfocus Mo-target X-ray tube $(\lambda=0.71073 \AA$ A $)$ and PHOTON 100 CMOS detector. Data reduction and integration were performed with the Bruker APEX3 software package (Bruker AXS, version 2017.3-0, 2018). Data were scaled and corrected for absorption effects using the multi-scan procedure as implemented in SADABS (Bruker AXS, version 2016/2). ${ }^{1}$ The structure was solved by SHELXT (Version 2018/2) ${ }^{2}$ and refined by a full-matrix least-squares procedure using OLEX2 (XL refinement program version 2018/3). ${ }^{3,4}$ Structure refinement was performed with the SHELXL program package integrated in OLEX2. Disorder was observed in the structure with approximately $6 \%$ occupancy of the minor position and modeled in the Ni center only due 
to the high electron density of Ni relative to other atoms in the structure. Crystallographic data are presented in the following table.

Table S1. Crystallographic data for $\mathbf{1}$.

Empirical formula

Formula weight

Temperature/K

Crystal system

Space group

$\mathrm{a} / \AA$

$\mathrm{b} / \AA$

$\mathrm{c} / \AA$

$\alpha /^{\circ}$

$\beta /^{\circ}$

$\gamma /{ }^{\circ}$

Volume $/ \AA^{3}$

$\mathrm{Z}$

$\rho_{\text {calcg }} / \mathrm{cm}^{3}$

$\mu / \mathrm{mm}^{-1}$

$\mathrm{F}(000)$

Crystal size $/ \mathrm{mm}^{3}$

Radiation

$2 \Theta$ range for data collection ${ }^{\circ}$

Index ranges

Reflections collected

Independent reflections

Data/restraints/parameters

Goodness-of-fit on $\mathrm{F}^{2}$

Final R indexes [I>=2 $\sigma(\mathrm{I})]$

Final R indexes [all data]

Largest diff. peak/hole / e $\AA^{-3}$
$\mathrm{C}_{28} \mathrm{H}_{37.2 \mathrm{NNiP}}$

477.46

$100(2)$

orthorhombic

Pbca

$15.2818(7)$

15.9683(8)

20.1652(9)

90

90

90

4920.8(4)

8

1.289

0.869

2042.0

$0.561 \times 0.39 \times 0.322$

$\operatorname{MoK} \alpha(\lambda=0.71073)$

4.206 to 65.212

$-22 \leq \mathrm{h} \leq 22,-24 \leq \mathrm{k} \leq 24,-29$

$\leq \mathrm{l} \leq 30$

120239

$8865\left[\mathrm{R}_{\text {int }}=0.0472, \mathrm{R}_{\text {sigma }}=\right.$ $0.0265]$

$8865 / 0 / 291$

1.162

$\mathrm{R}_{1}=0.0496, \mathrm{wR}_{2}=0.1116$

$\mathrm{R}_{1}=0.0703, \mathrm{wR}_{2}=0.1183$

$0.84 /-0.33$ 


\section{Characterizations of Bi-PNPh}

$\underbrace{\mathrm{Ph}}_{P\left({ }^{t} \mathrm{Bu}\right)_{2}}$

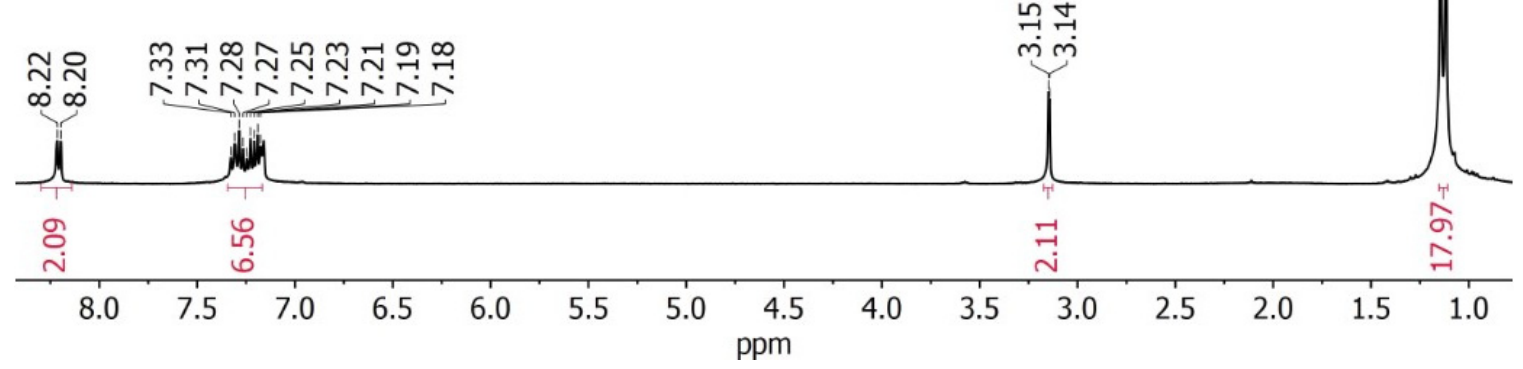

Figure S6. ${ }^{1} \mathrm{H}$ NMR of PNPh in $\mathrm{C}_{6} \mathrm{D}_{6}$. The aromatic multiplet integrates slightly higher than the expected 6 protons, due to solvent overlap. 
<smiles>CCCCCc1nc(-c2ccccc2)ccc1-c1ccc(-c2ccccc2)nc1CPC(C)(C)C</smiles>

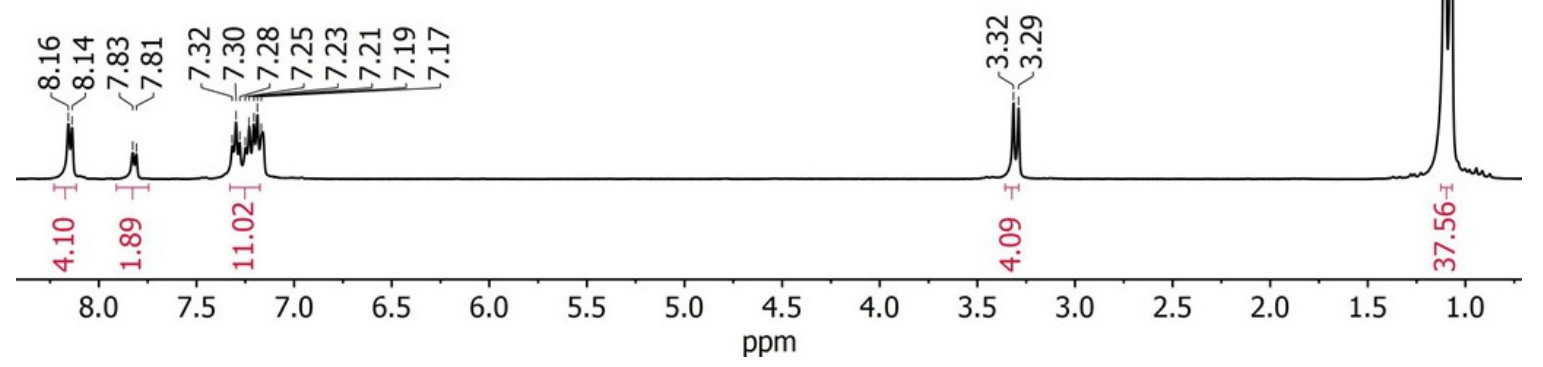

Figure S7. ${ }^{1} \mathrm{H}$ NMR of bi-PNPh in $\mathrm{C}_{6} \mathrm{D}_{6}$. The aromatic multiplet integrates higher than the expected 8 protons, due to solvent peak overlap and minor contaminants. The ${ }^{t} \mathrm{Bu}$ doublet integrates higher than the expected 36 protons, due to solvent peak overlap and minor contaminants.

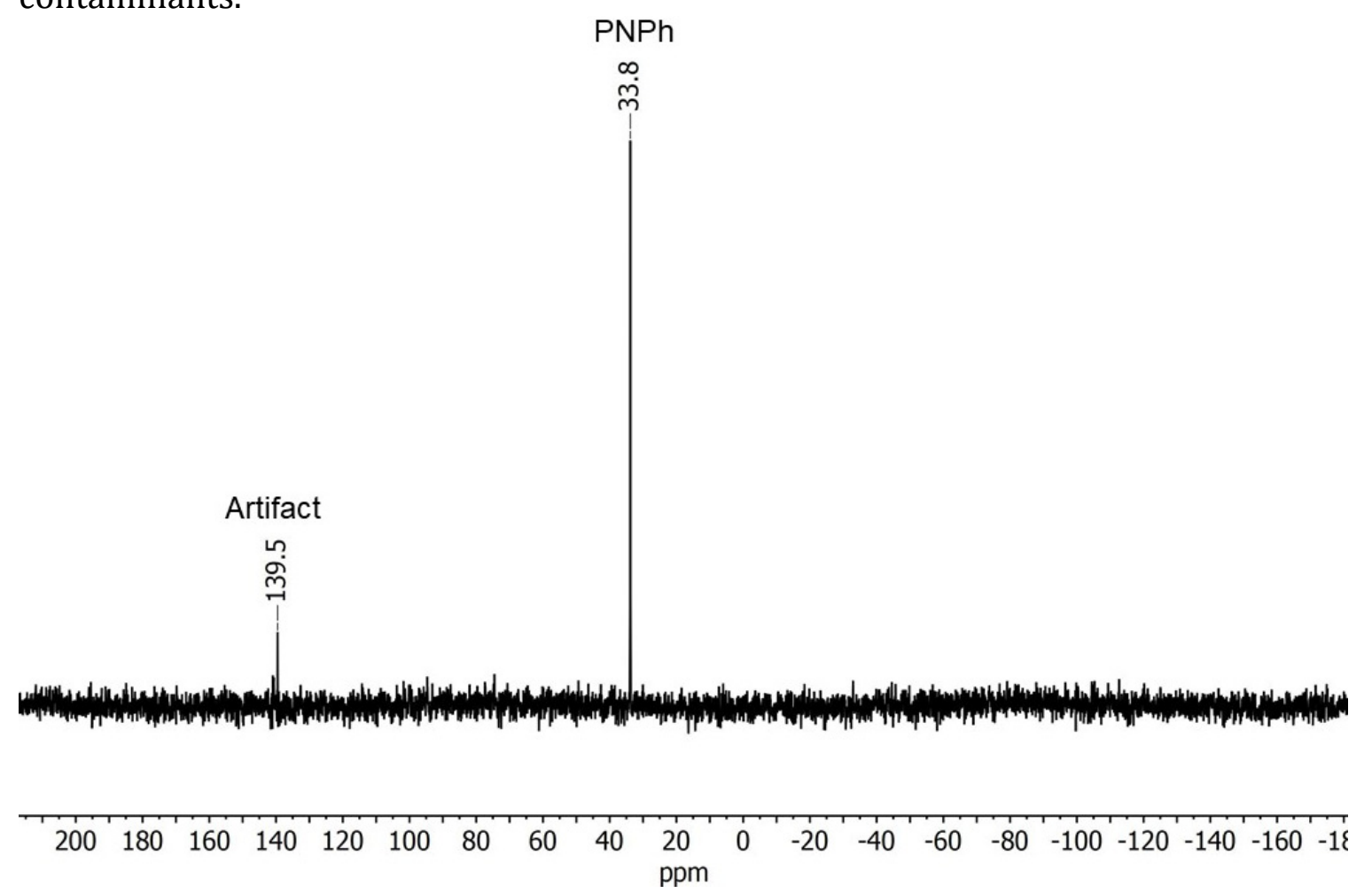

Figure S8. ${ }^{31} \mathrm{P}$ NMR of $\mathrm{PNPh}$ in $\mathrm{C}_{6} \mathrm{D}_{6}$. The signal at $140 \mathrm{ppm}$ is an instrument artifact that is noticeable in more dilute samples. 


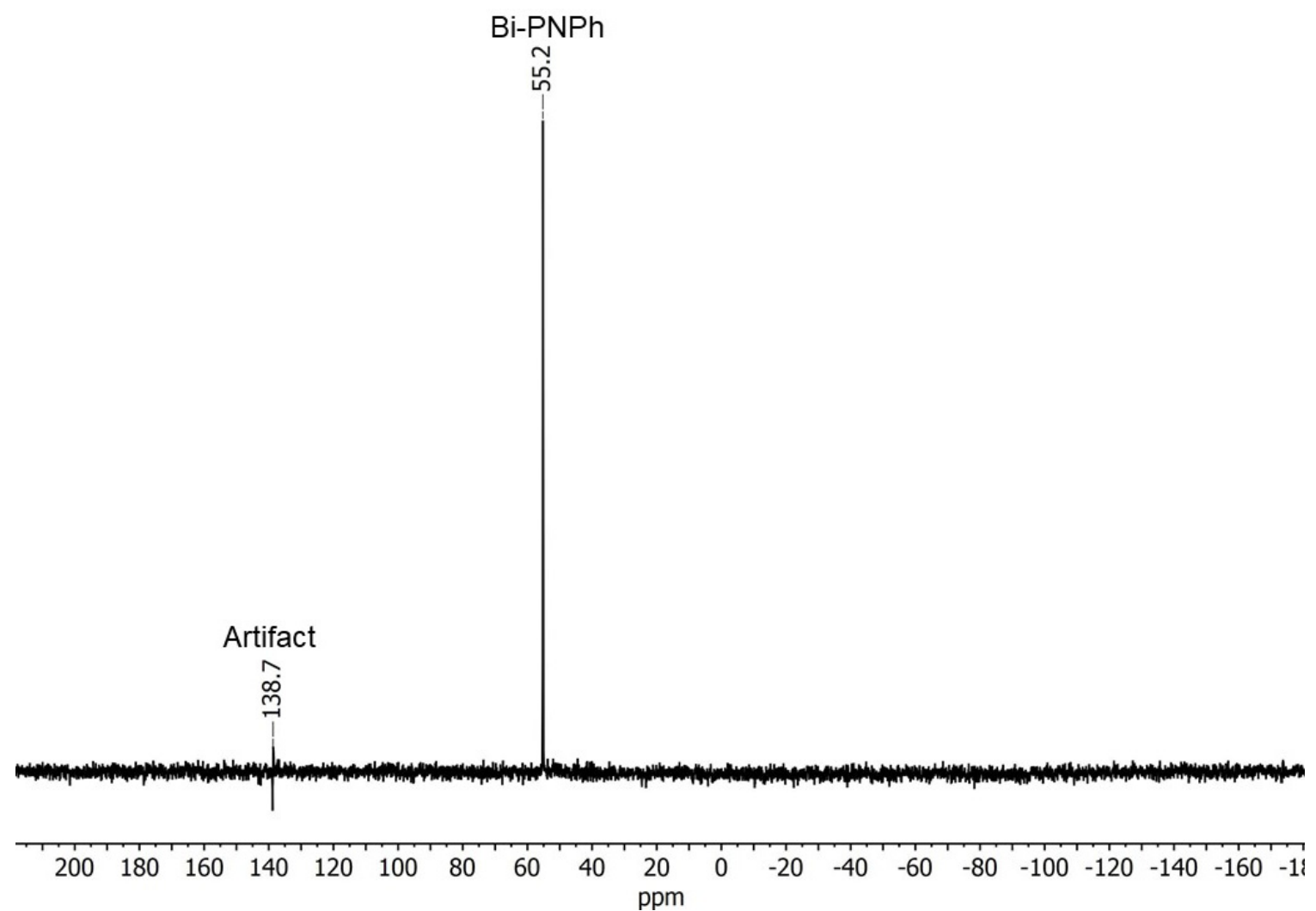

Figure S9. ${ }^{31} \mathrm{P}$ NMR of bi-PNPh in $\mathrm{C}_{6} \mathrm{D}_{6}$.

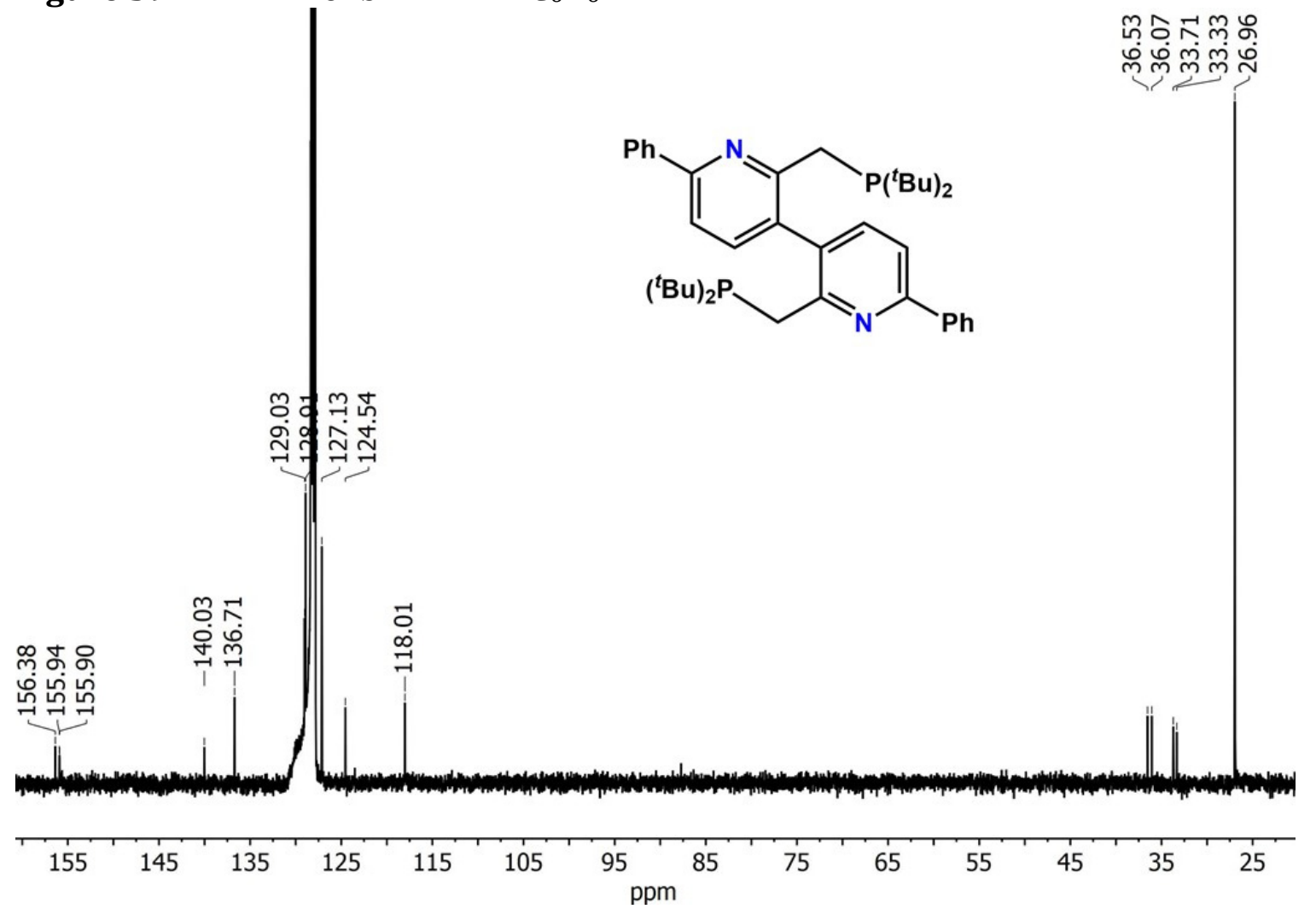

Figure S10. ${ }^{13} \mathrm{C}$ NMR of bi-PNPh in $\mathrm{C}_{6} \mathrm{D}_{6}$. 

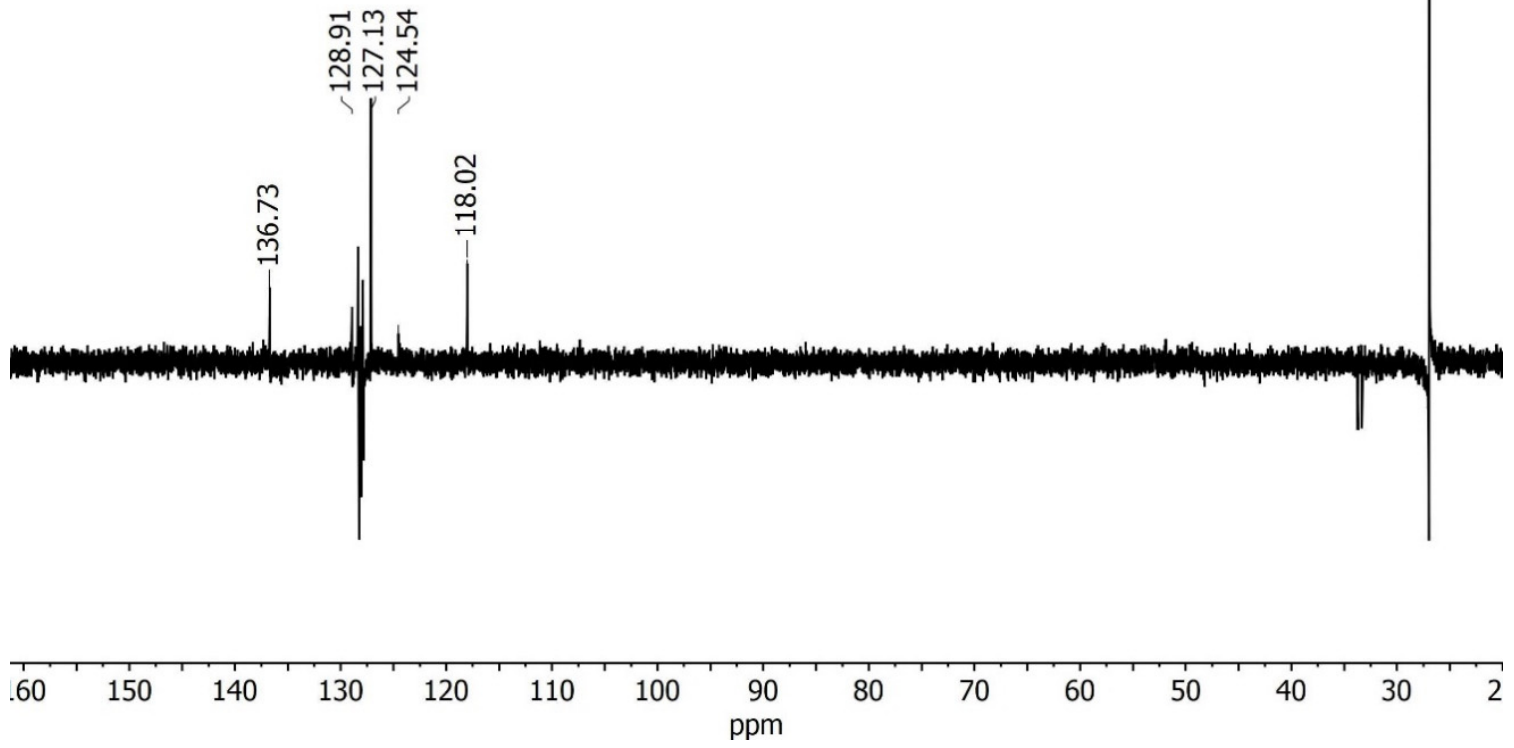

Figure S11. ${ }^{13} \mathrm{C}$ DEPT-135 NMR of bi-PNPh in $\mathrm{C}_{6} \mathrm{D}_{6}$.
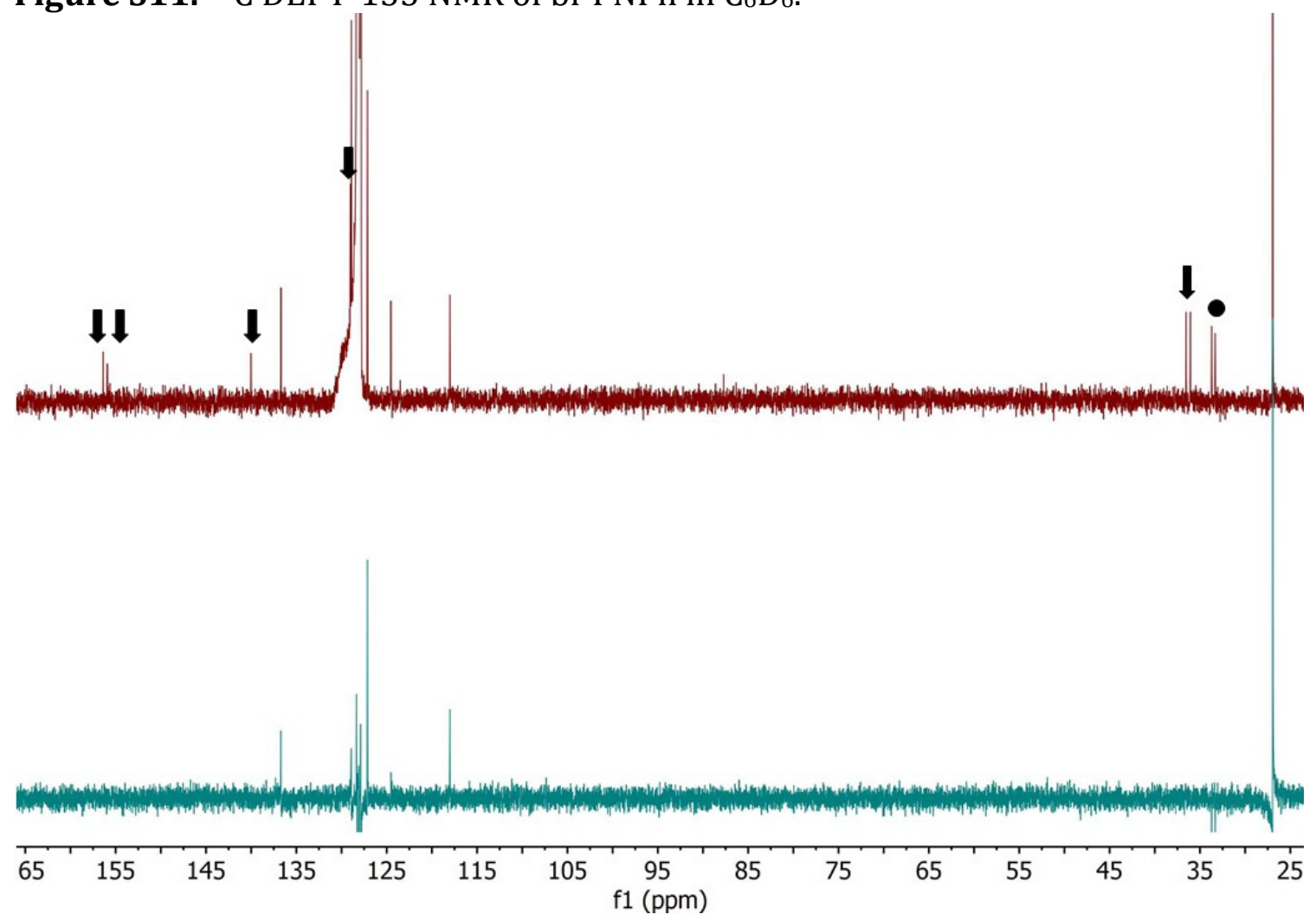
Figure S12. ${ }^{13} \mathrm{C}$ NMR and ${ }^{13} \mathrm{C}$ DEPT- $135 \mathrm{NMR}$ of bi-PNPh in $\mathrm{C}_{6} \mathrm{D}_{6}$. Black arrows designate signals corresponding to quaternary carbons, and the black dot designates the signal corresponding to the methylene carbon.
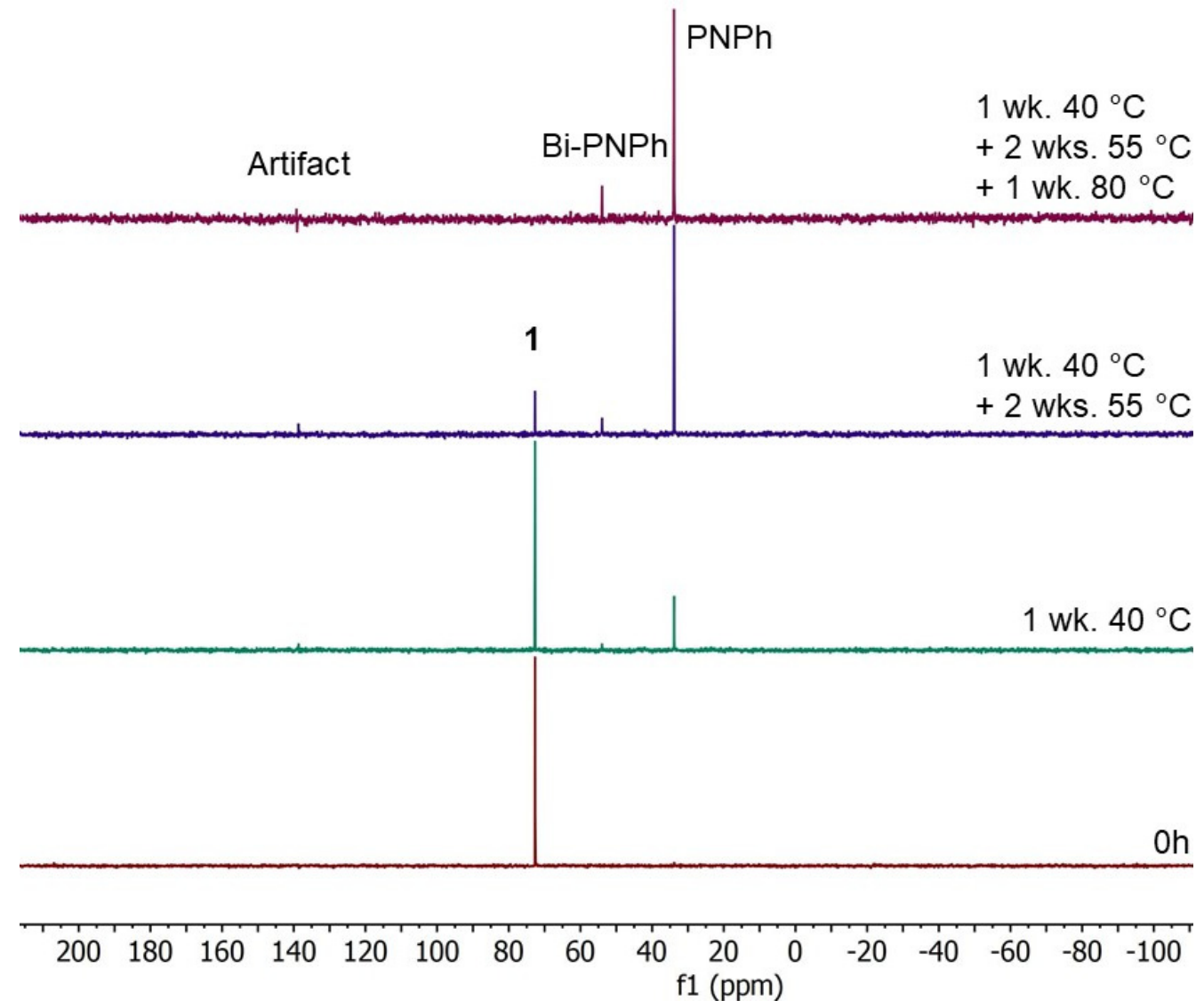

Figure S13. Sequential ${ }^{31} \mathrm{P}$ NMR of sealed thermolysis of $\mathbf{1}$ in toluene. 


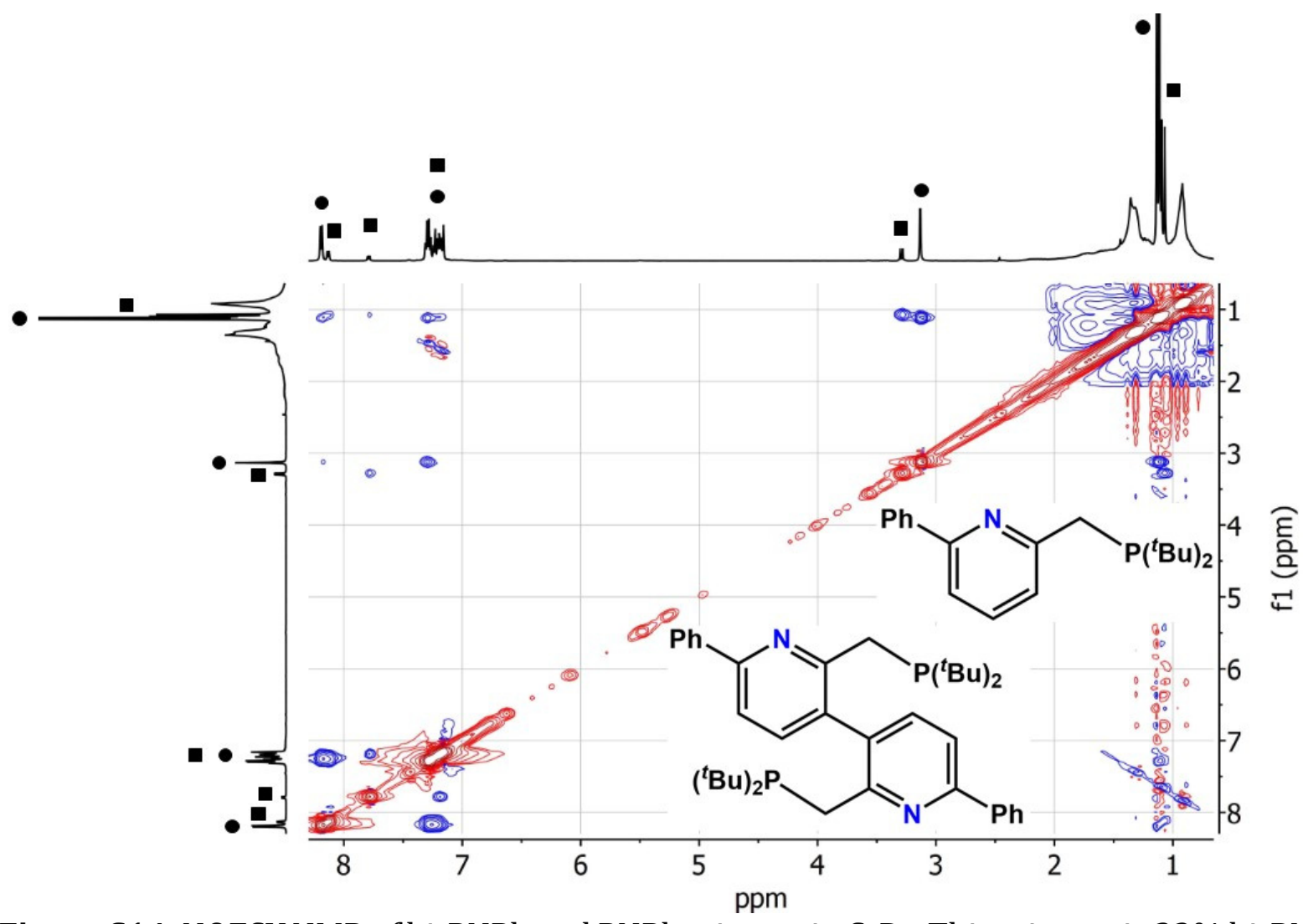

Figure S14. NOESY NMR of bi-PNPh and PNPh mixture in $\mathrm{C}_{6} \mathrm{D}_{6}$. This mixture is $23 \%$ bi-PNPh, $77 \%$ PNPh by ${ }^{31} \mathrm{P}$ NMR. The circles correspond to PNPh signals, and the squares correspond to bi-PNPh signals. Two large alkane grease peaks around the ${ }^{t} \mathrm{Bu}$ resonances are unlabeled.

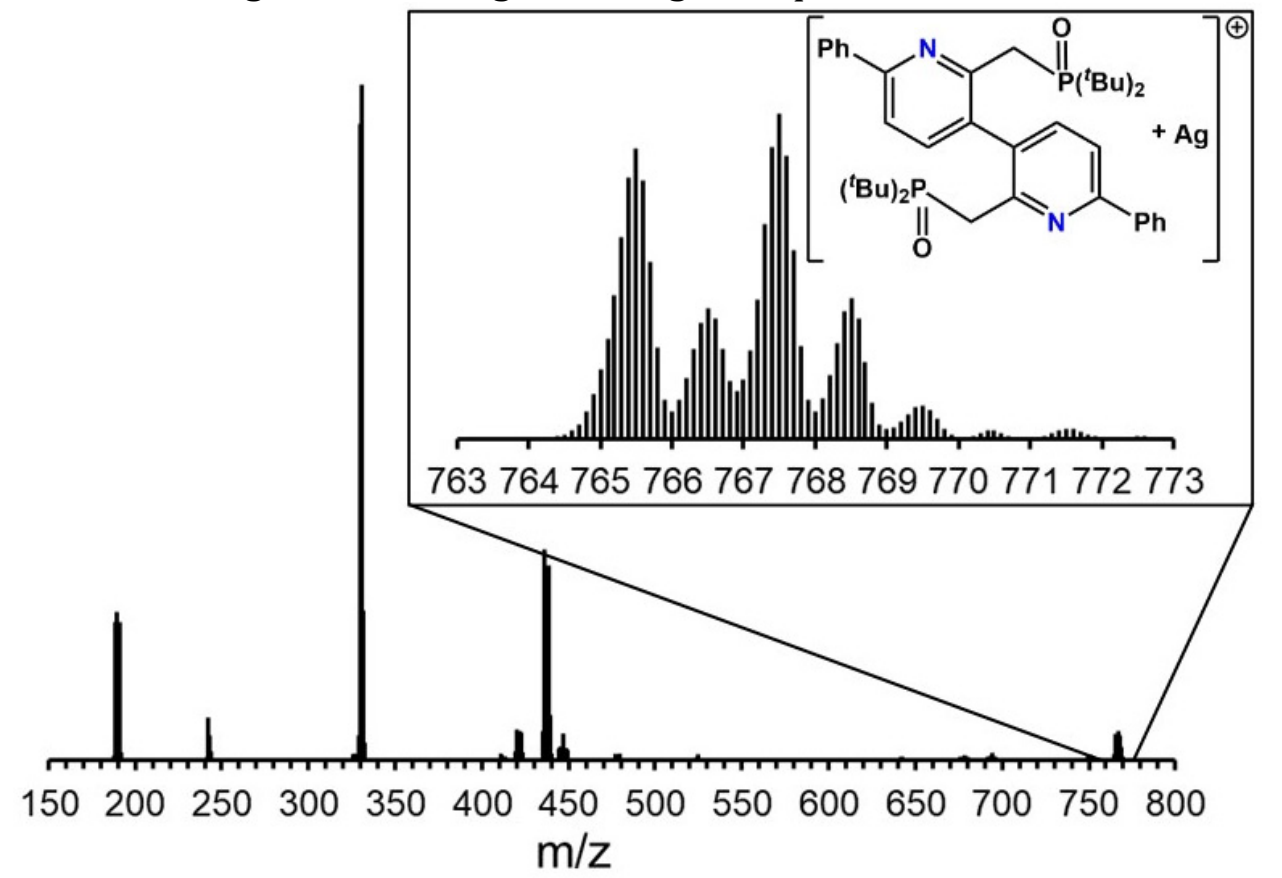

Figure S15. MS data from ESI-MS analysis of bi-PNPh and PNPh mixture + AgOTf. This mixture is $80 \%$ bi-PNPh, $20 \%$ PNPh by ${ }^{31} \mathrm{P}$ NMR. The inset shows the signal for doubly airoxidized bi-PNPh with the mass and pattern indicative of an $\mathrm{Ag}^{+}$-inclusive fragment. 


\section{Pulsed Gradient Spin-Echo NMR}

\section{Experiment Description}

PGSE measurements were performed on a Bruker $500 \mathrm{MHz}$ spectrometer using the StejskalTanner method. The spin-echo sequence included one pulsed field gradient before the $180^{\circ}$ pulse and one after, each with the same duration $\delta$, separated by a delay time $\Delta$. For each ${ }^{1} \mathrm{H}$ spectrum collection, the z-gradient percentage was varied from $0 \%$ to $40 \%$, in increments of $5 \%$. The gradient calibration was taken from data of a $2 \%$ solution of $\mathrm{H}_{2} \mathrm{O}$ in $\mathrm{D}_{2} \mathrm{O}^{5}$ One experiment was conducted on pure PNPh and signal decay was analyzed using the $m$ - $\mathrm{Ph}$ resonance integration. Another experiment was conducted on a bi-PNPh and PNPh mixture, $23 \%$ bi-PNPh and 77\% PNPh by ${ }^{31} \mathrm{P} \mathrm{NMR}$, and signal decay was analyzed using the $p$-pyridine resonance integration. A linear plot of $\ln \left(\mathrm{Ig}_{\mathrm{g}} / \mathrm{I}_{0}\right)\left(\mathrm{Ig}=\right.$ integration of the peak in the gradient, $\mathrm{I}_{0}$ = integration of the peak in $0 \%$ gradient) versus the squared z-gradient field strength $G_{z}{ }^{2}$ was generated. The slope of this line can be used to calculate the diffusion coefficient (Equation 1 ), and the diffusion coefficient can be used to estimate the hydrodynamic radius by the Stokes-Einstein equation (Equation 2). ${ }^{6}$ A spherical hydrodynamic volume was estimated (Equation 3). A shape factor correction (Equation 4) was used to estimate a different equivalent hydrodynamic radius for prolate ellipsoids (Equation 5). A hydrodynamic volume was estimated for this corrected radius (Equation 3).

$\ln \left(I_{g} / I_{0}\right)=\left[-\gamma^{2} \delta^{2}(\Delta-\delta / 3)\right] D G_{z}^{2}$

$D=k_{B} T / \chi \pi \eta R_{H}$

$V_{H}=4 \pi R_{H}^{3} / 3$

$F=\sqrt{p^{2}-1} /\left(p^{\frac{1}{3}} \ln \left[p+\sqrt{p^{2}-1}\right]\right)$

$R_{H}=F R_{H}^{e l}$

Both PNPh and bi-PNPh were modeled in the HyperChem software using Polak-Ribiere molecular mechanics optimization. (Version 8.0.7). ${ }^{7}$ The dimensions of each model were roughly measured for prolate ellipsoid shape factor correction. The quantitative structureactivity relationship- (QSAR-)modelled volume of each compound was calculated in this software and then used to estimate the expected ratio of monomer $V_{H}$ to dimer $V_{H}$. This ratio was compared to that calculated from the experimental data. All calculations are presented in the table below. 


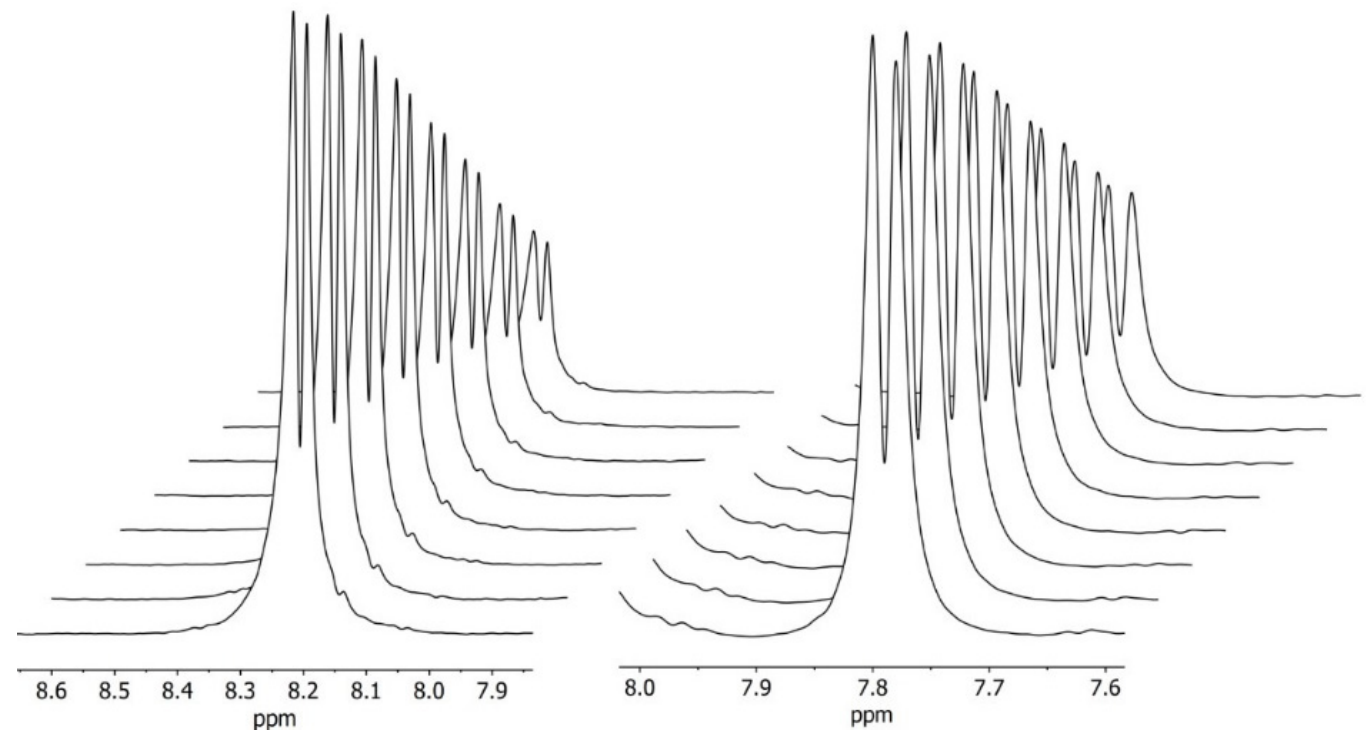

Figure S16. Signal decay of PNPh peak (left) and bi-PNPh peak (right) in $\mathrm{C}_{6} \mathrm{D}_{6}$.

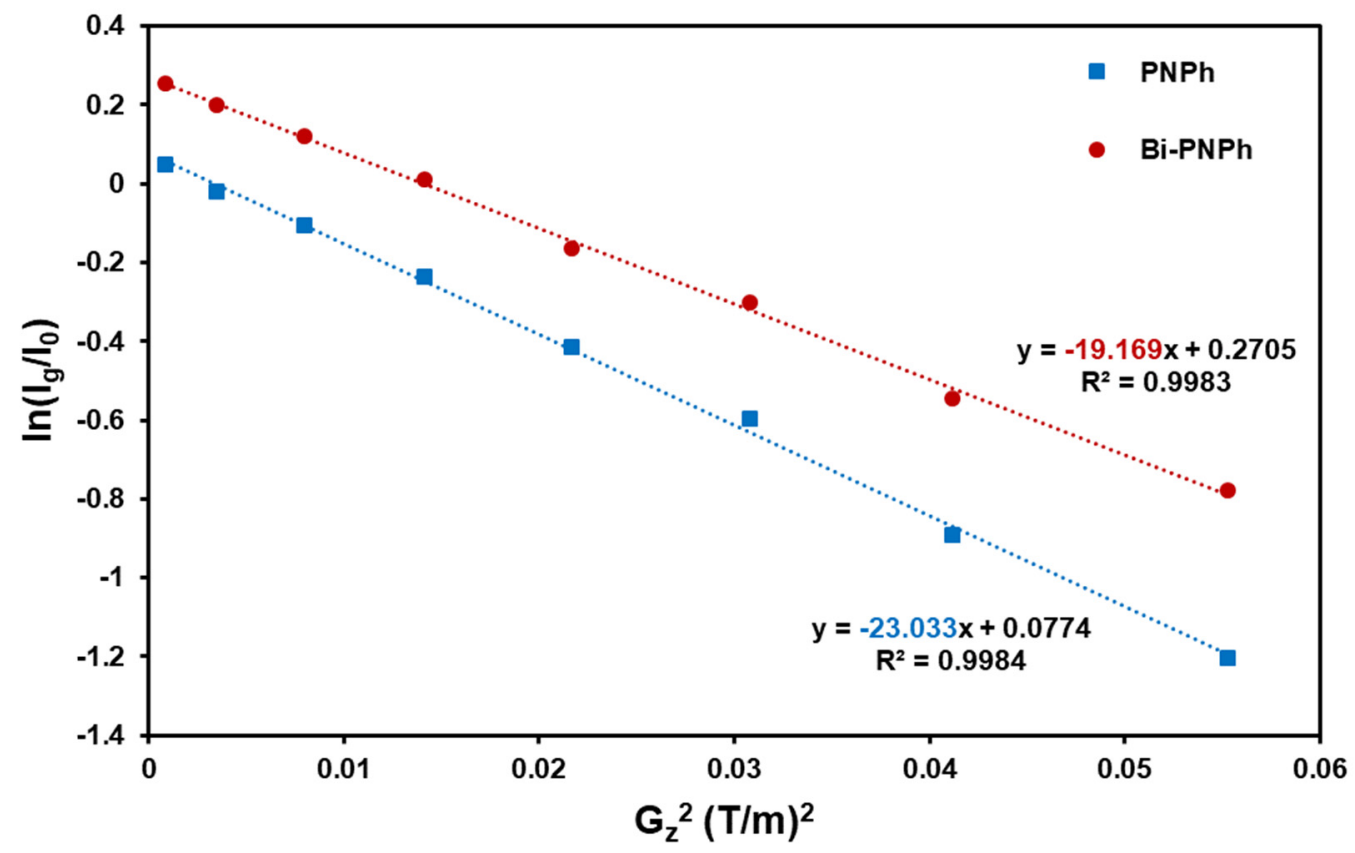

Figure S17. Stejskal Tanner Plot of bi-PNPh and PNPh data. 
Table S2. PGSE Calculations.

\begin{tabular}{|c|c|}
\hline Variable & Value \\
\hline Gyromagnetic ratio of a proton: $\gamma$ [radians/(T.s)] & $2.675222 \cdot 10^{8}$ \\
\hline Gradient duration: $\delta[\mathrm{s}]$ & 0.004 \\
\hline Boltzmann constant: $k_{B}\left[\left(\mathrm{~kg} \cdot \mathrm{m}^{2}\right) /\left(\mathrm{K} \cdot \mathrm{s}^{2}\right)\right]$ & $1.3806 \cdot 10^{-23}$ \\
\hline Temperature: $T[\mathrm{~K}]$ & 298 \\
\hline Hydrodynamic boundary conditions: $\chi$ & 4 \\
\hline Solvent dynamic viscosity: $\eta[\mathrm{Pa} \cdot \mathrm{s}]$ & 0.000636 \\
\hline PNPh diffusion time: $\Delta[\mathrm{s}]$ & 0.0141267 \\
\hline PNPh diffusion coefficient: $D\left[\mathrm{~m}^{2} / \mathrm{s}\right]$ & $1.57 \cdot 10^{-9}$ \\
\hline PNPh hydrodynamic radius: $R_{H}[\AA]$ & 3.27 \\
\hline PNPh spherical hydrodynamic volume: $V_{H}\left[\AA^{3}\right]$ & 147 \\
\hline PNPh aspect ratio: $p$ & 1.7 \\
\hline PNPh ellipsoid shape factor: $F$ & 1.025 \\
\hline $\begin{array}{l}\text { PNPh ellipsoid hydrodynamic radius of sphere of } \\
\text { equivalent volume: } R_{H^{e l}}[\AA]\end{array}$ & 3.19 \\
\hline PNPh ellipsoid hydrodynamic volume: $V_{H}\left[\AA^{3}\right]$ & 137 \\
\hline PNPh modeled QSAR volume: $\left[\AA^{3}\right]$ & 942 \\
\hline Bi-PNPh diffusion time: $\Delta[\mathrm{s}]$ & 0.014128 \\
\hline Bi-PNPh diffusion coefficient: $D\left[\mathrm{~m}^{2} / \mathrm{s}\right]$ & $1.31 \cdot 10^{-9}$ \\
\hline Bi-PNPh hydrodynamic radius: $R_{H}[\AA]$ & 3.93 \\
\hline Bi-PNPh spherical hydrodynamic volume: $V_{H}\left[\AA^{3}\right]$ & 255 \\
\hline Bi-PNPh aspect ratio: $p$ & 1.5 \\
\hline Bi-PNPh ellipsoid shape factor: $F$ & 1.015 \\
\hline $\begin{array}{l}\text { Bi-PNPh ellipsoid hydrodynamic radius of sphere of } \\
\text { equivalent volume: } R H^{e l}[\AA \AA\end{array}$ & 3.88 \\
\hline Bi-PNPh ellipsoid hydrodynamic volume: $V_{H}\left[\AA^{3}\right]$ & 237 \\
\hline Bi-PNPh modeled QSAR volume: $\left[\AA^{3}\right]$ & 1750 \\
\hline QSAR volumes bi-PNPh:PNPh ratio & 1.86 \\
\hline Sphere volumes bi-PNPh:PNPh ratio & $\begin{array}{l}1.73(6.99 \% \text { error from QSAR } \\
\text { volumes ratio) }\end{array}$ \\
\hline Ellipsoid volumes bi-PNPh:PNPh ratio & $\begin{array}{l}1.73(6.99 \% \text { error from QSAR } \\
\text { volumes ratio) }\end{array}$ \\
\hline
\end{tabular}




\section{Identification of Volatile Final Products}

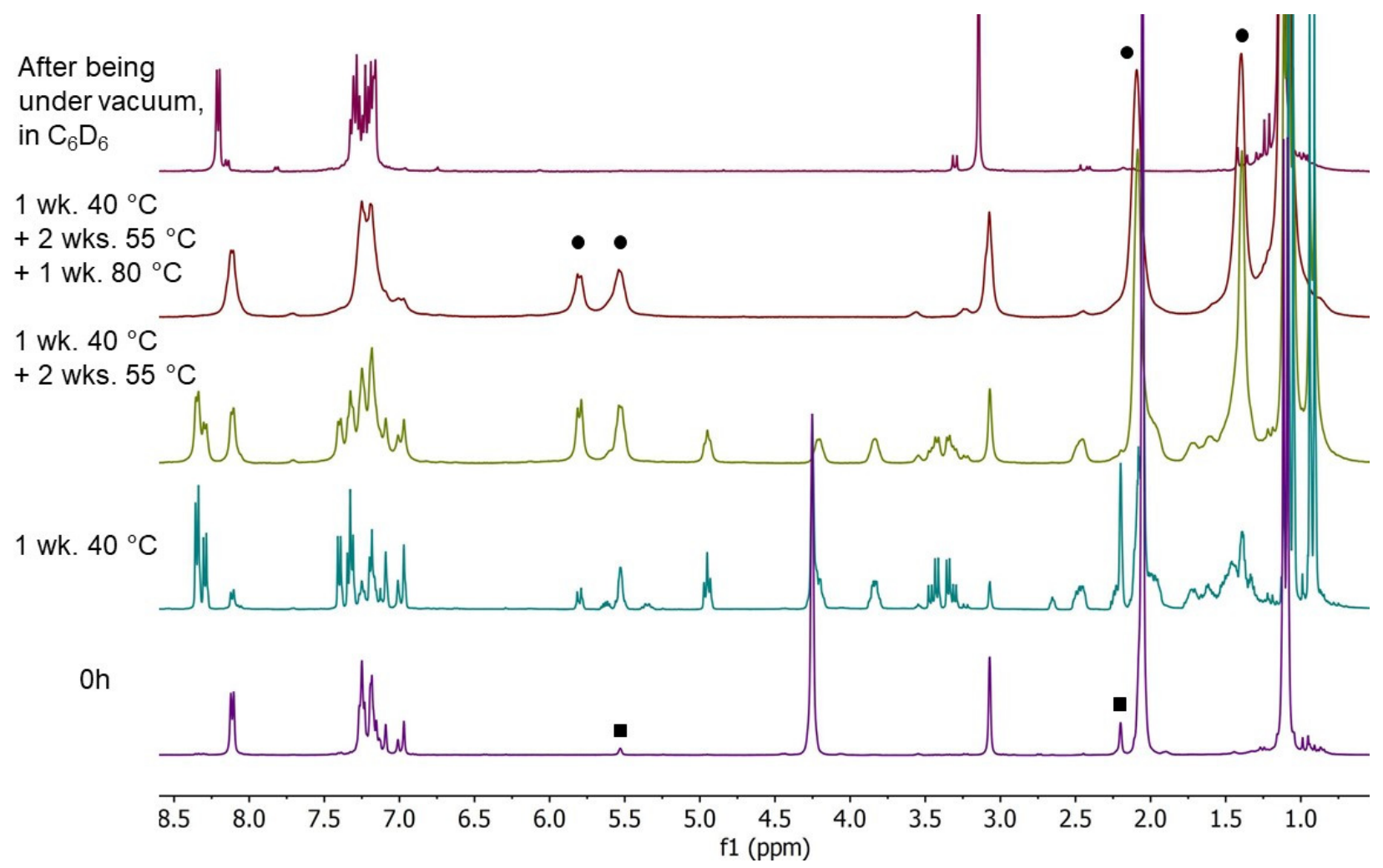

Figure S18. Sequential ${ }^{1} \mathrm{H}$ NMR of sealed long-term Ni(COD) $2+\mathrm{PNPh}$ reaction in toluene-d8. The metallic precipitate causes broader signals in later spectra. 1,5-COD resonances are signified by squares in one spectrum. It was also present as a minor contaminant in the starting material. 1,3-cyclooctadiene resonances are signified by circles in one spectrum. The final composition of P-containing compounds is $10 \%$ bi-PNPh and $90 \% \mathrm{PNPh}$ by ${ }^{31} \mathrm{P}$ NMR integration. COE signals cannot definitively be identified, due to broad signal overlap. 


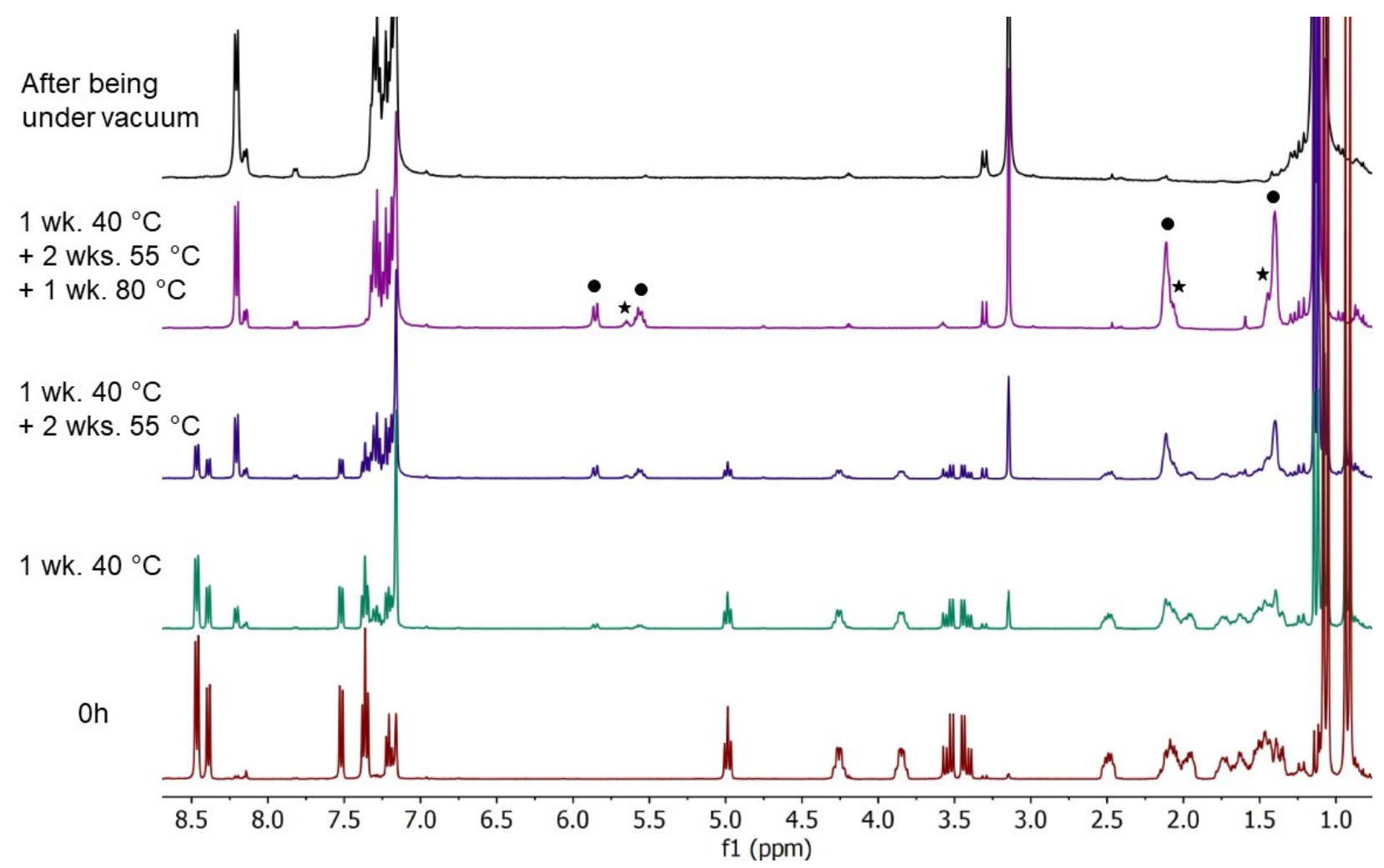

Figure S19. Sequential ${ }^{1} \mathrm{H}$ NMR of sealed thermolysis of 1 in $\mathrm{C}_{6} \mathrm{D}_{6}$. 1,3-cyclooctadiene resonances are signified by circles in one spectrum. COE resonances are signified by stars in one spectrum. The final composition of P-containing compounds is $14 \%$ bi-PNPh and $86 \%$ PNPh by ${ }^{31}$ P NMR integration. 


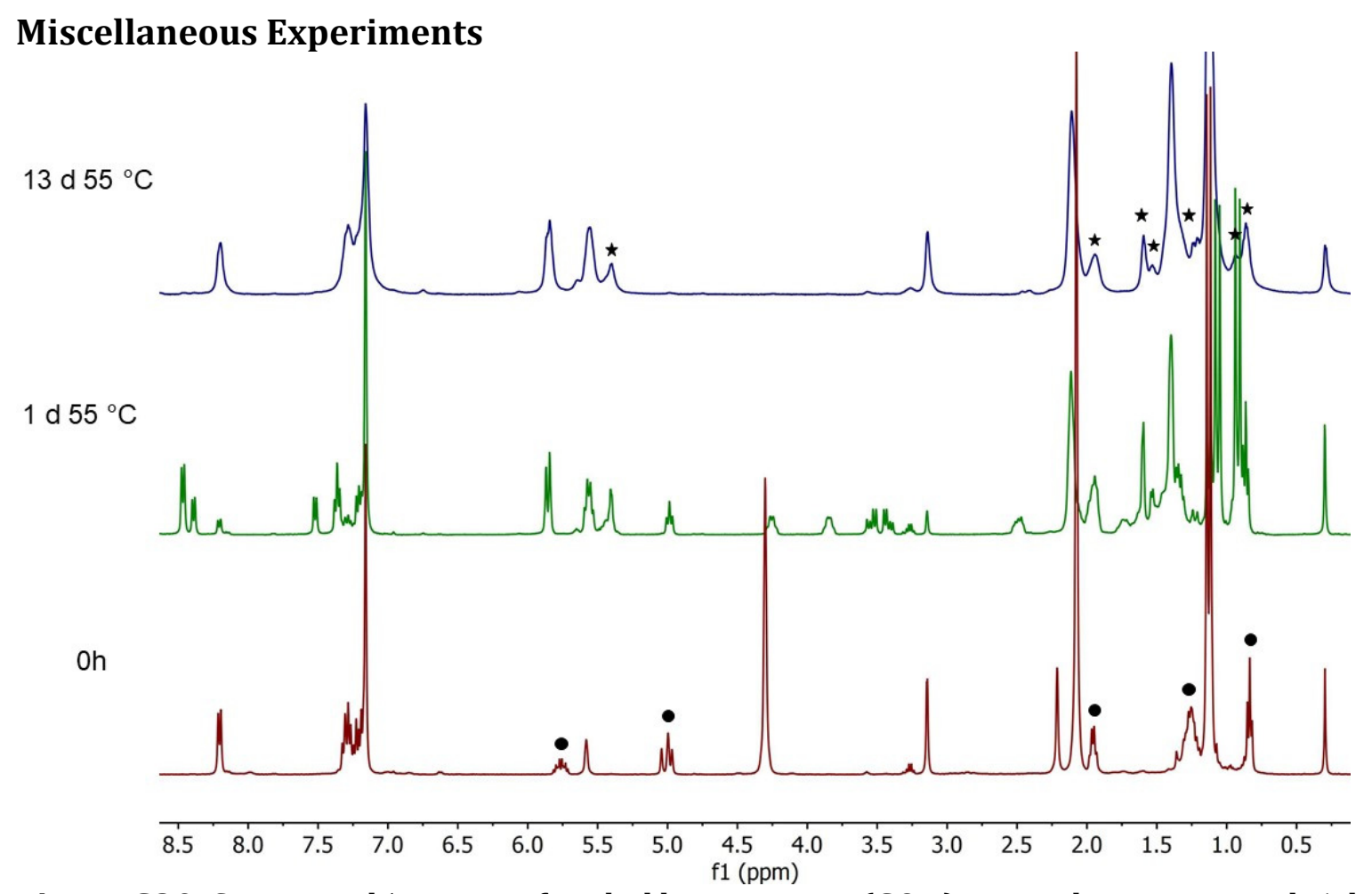

Figure S20. Sequential ${ }^{1} \mathrm{H}$ NMR of sealed long-term $\mathrm{Ni}(\mathrm{COD})_{2}+\mathrm{PNPh}$ reaction with 1-hexene in $\mathrm{C}_{6} \mathrm{D}_{6}$. 1-hexene resonances are signified by circles in the bottom spectrum. 2- and 3-hexene resonances are signified by stars in the top spectrum.

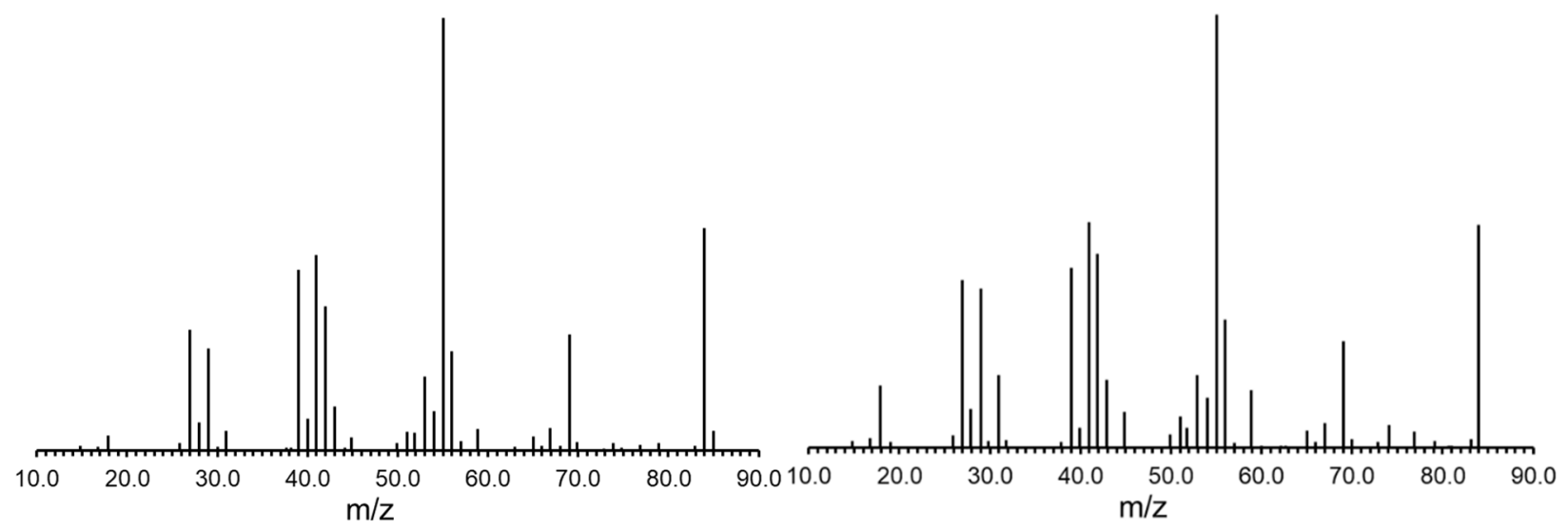

Figure S21. MS data of 2- and 3-hexene from GC-MS analysis of long-term Ni(COD) $2+\mathrm{PNPh}$ reaction with 1 -hexene. 


\section{Reactivity Studies of 1}

Table S3. Summary of reactivity studies of $\mathbf{1 .}$

\begin{tabular}{|c|c|c|c|}
\hline Reagent & $\begin{array}{l}\text { Temp.; } \\
\text { Duration }\end{array}$ & Products & Relative Amount (\%) \\
\hline $\begin{array}{l}\mathrm{PhMgBr} \\
(3.0 \mathrm{M} \text { in } \\
\left.\mathrm{Et}_{2} \mathrm{O}\right)\end{array}$ & $\begin{array}{l}\text { RT; } \\
\text { overnight }\end{array}$ & $\mathbf{1}$ (net product) & $\sim 100$ \\
\hline \multirow[t]{4}{*}{ MeI } & \multirow[t]{4}{*}{$55^{\circ} \mathrm{C} ; 5 \mathrm{~d}$} & $(\mathrm{PNPh}) \mathrm{NiX}^{\mathrm{b}}$ & 67 \\
\hline & & $\mathrm{PNPh}$ & 24 \\
\hline & & Me-PNPh & 7 \\
\hline & & $\mathrm{Bi}-\mathrm{PNPh}$ & 2 \\
\hline \multirow[t]{3}{*}{$\mathrm{PhI}$} & \multirow[t]{3}{*}{$55^{\circ} \mathrm{C} ; 5 d$} & $\mathrm{PNPh}$ & 82 \\
\hline & & $(\mathrm{PNPh}) \mathrm{NiX}^{\mathrm{b}}$ & 16 \\
\hline & & $\mathrm{Bi}-\mathrm{PNPh}$ & 2 \\
\hline
\end{tabular}

aMixture composition determined by ${ }^{1} \mathrm{H}$ NMR integration only considering P-containing products.

bSee note on (PNPh)NiX formulation below Figure S24. 


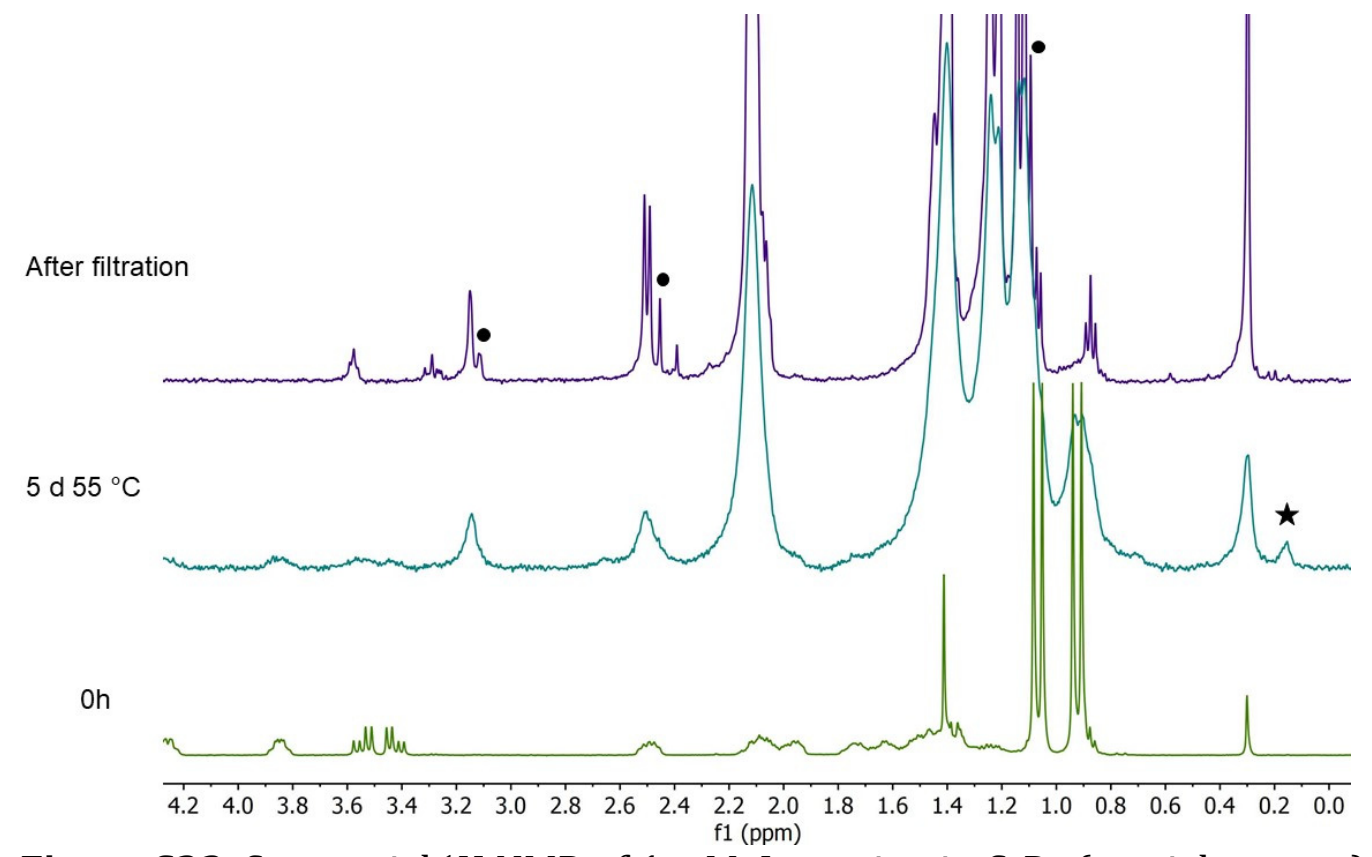

Figure S22. Sequential ${ }^{1} \mathrm{H}$ NMR of $1+$ MeI reaction in $\mathrm{C}_{6} \mathrm{D}_{6}$ (partial spectra). The $\mathrm{CH}_{4}$ signal is indicated by a star in the middle spectrum. The signals assigned to methylene, methyl, and ${ }^{t} \mathrm{Bu}$ groups of Me-PNPh are indicated by circles in the top spectrum. These were assigned based on shift and relative integrations. 

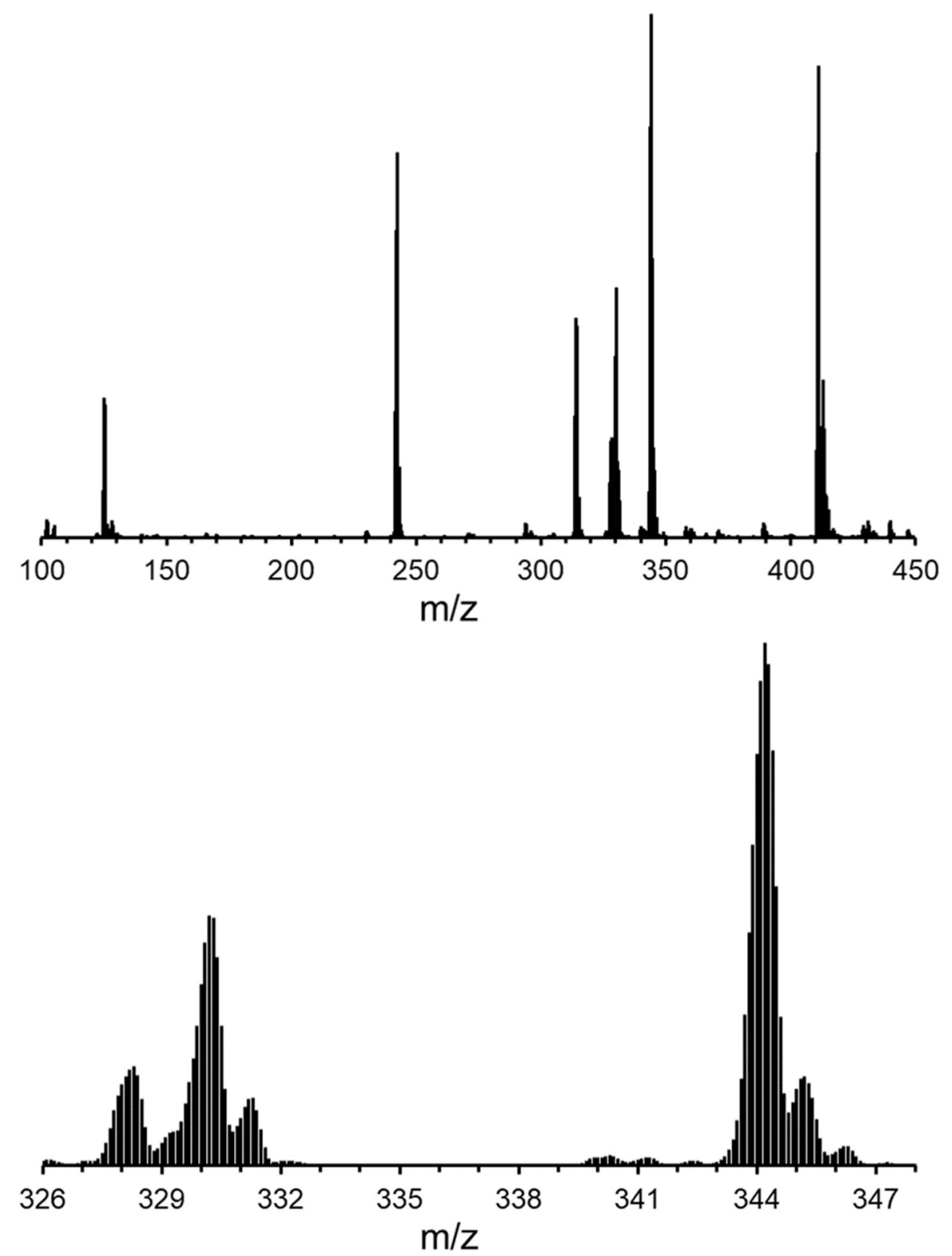

Figure S23. MS data from ESI-MS analysis of $\mathbf{1}+$ MeI reaction products. The bottom partial spectrum shows the signal assigned to Me-PNPh at $328 \mathrm{~m} / \mathrm{z}$ units and the signal assigned to oxidized Me-PNPh at $344 \mathrm{~m} / \mathrm{z}$ units. (Oxidized PNPh overlaps at $330 \mathrm{~m} / \mathrm{z}$ units). 


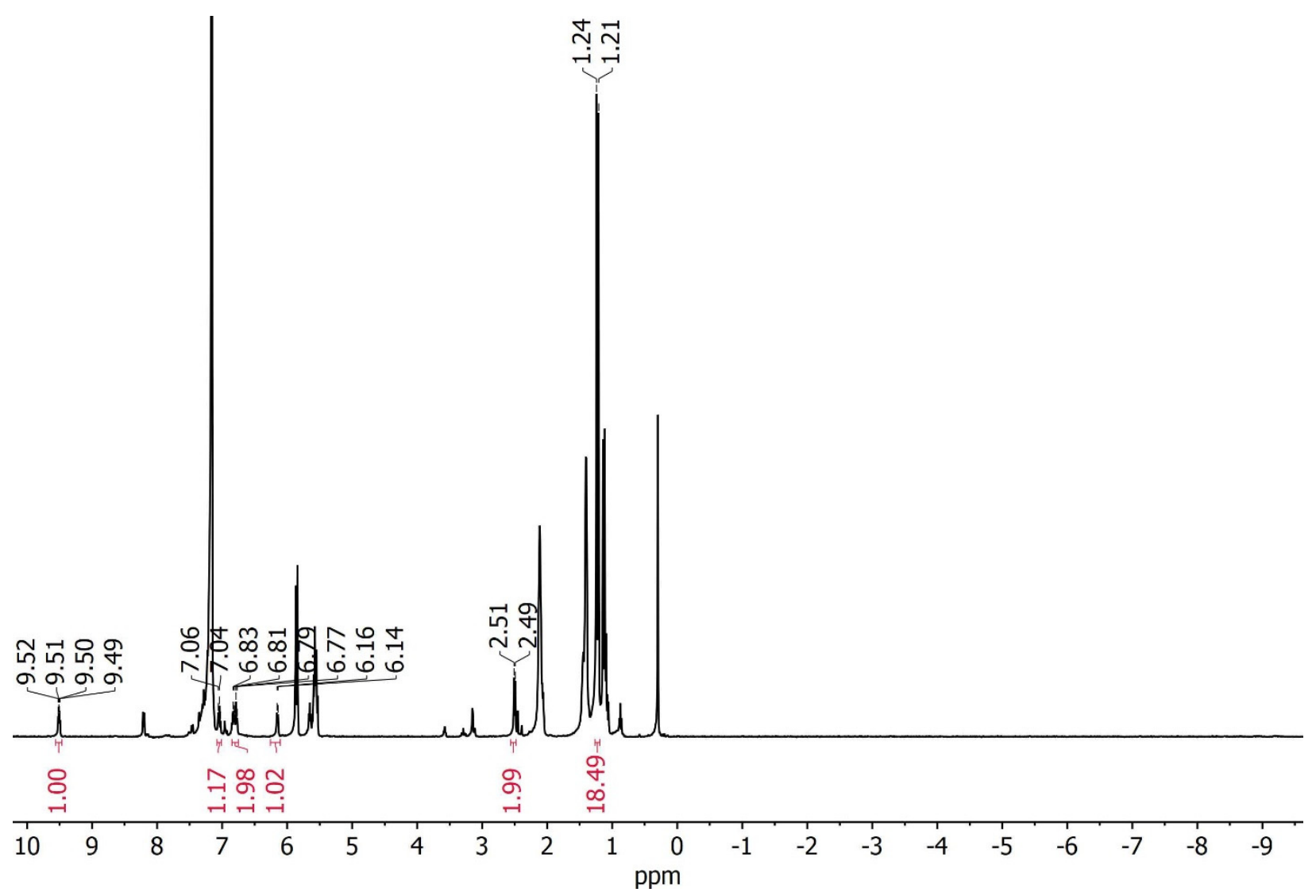

Figure S24. ${ }^{1} \mathrm{H}$ NMR of 1 + MeI reaction mixture in $\mathrm{C}_{6} \mathrm{D}_{6}$ after filtration. The peaks tentatively assigned to (PNPh)NiX are labeled and integrated. Two aromatic protons are missing, perhaps covered by other product and solvent signals.

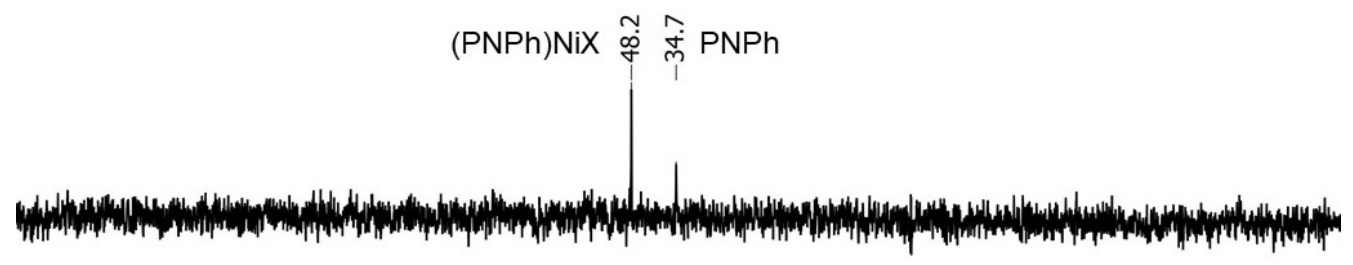

$\begin{array}{llllllllllllllllllllllll}220 & 200 & 180 & 160 & 140 & 120 & 100 & 80 & 60 & 40 & 20 & 0 & -20 & -40 & -60 & -80 & -100 & -120 & -140 & -161\end{array}$

Figure S25. ${ }^{31} \mathrm{P}$ NMR of $1+\mathrm{MeI}$ reaction mixture in $\mathrm{C}_{6} \mathrm{D}_{6}$ after filtration. The signal assigned to (PNPh)NiX is at $48 \mathrm{ppm}$, while the PNPh signal can be seen at $34 \mathrm{ppm}$. The amounts of Me$\mathrm{PNPh}$ and bi-PNPh observed in the ${ }^{1} \mathrm{H}$ NMR spectrum are too small to distinguish reliable corresponding ${ }^{31} \mathrm{P}$ NMR signals from the spectrum noise. 
Note on (PNPh)NiX formulation -

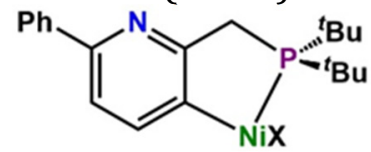

The main product of the reaction of $\mathbf{1}$ with $\mathrm{MeI}$, and a minor product of the same reaction with PhI, was a strongly colored red-orange material. This species was tentatively assigned based on ${ }^{1} \mathrm{H}$ NMR signals (Figure S24), a ${ }^{31} \mathrm{P}$ NMR signal at $48 \mathrm{ppm}$ (Figure S25), and an ESIMS signal at 411 and $413 \mathrm{mz} /$ units (Figure S23). The ESI-MS signal has the mass and isotope pattern of a $(\mathrm{PNPh}) \mathrm{Ni}(\mathrm{MeCN})^{+}$ion. This could result from ligand displacement of $\mathrm{X}^{-}$with $\mathrm{MeCN}$, the solvent in which the ESI-MS was run.

The ${ }^{1} \mathrm{H}$ NMR indicates that this species is diamagnetic, meaning it is likely $\mathrm{Ni}^{\mathrm{II}}$ with the aryl ligand and another $\mathrm{X}^{-}$ligand. Based on the reaction materials, $\mathrm{X}^{-}$could be $\mathrm{CH}_{3}^{-}, \mathrm{H}^{-}$, an anionic COD derivative, or I-

- $\mathrm{CH}_{3}{ }^{-}$was discounted because the same species was observed in reactions of $\mathbf{1}+\mathrm{PhI}$, in which no methylating agents were present.

- $\mathrm{H}^{-}$was discounted by the lack of hydride resonances, which should be observable in the ${ }^{1} \mathrm{H}$ NMR spectrum below $0 \mathrm{ppm}$. These were not observed, as shown in Figure S24 and verified in scans ranging to $-100 \mathrm{ppm}$.

- An anionic COD derivative seems unlikely, since the cyclooctenyl ligand of $\mathbf{1}$ has otherwise proven to be a strongly favored COD-derived ligand and the ${ }^{1} \mathrm{H}$ NMR shows this species is not $\mathbf{1}$.

- $\mathrm{I}^{-}$is the most likely identity of $\mathrm{X}^{-}$, considering its presence in solution in both the MeI and $\mathrm{PhI}$ reactions.

However, these data are far from conclusive, so the assignment of (PNPh)NiX is only tentative.

\section{References}

[1] Krause, L.; Herbst-Irmer, R.; Sheldrick, G. M.; Stalke, D. "Comparison of Silver and Molybdenum Microfocus X-Ray Sources for Single-Crystal Structure Determination." J. Appl. Crystallogr. 2015, 48 (1), 3-10.

[2] Sheldrick, G. M. "SHELXT - Integrated Space-Group and Crystal-Structure Determination." Acta Crystallogr. Sect. A Found. Crystallogr. 2015, 71 (1), 3-8.

[3] Dolomanov, O. V; Bourhis, L. J.; Gildea, R. J.; Howard, J. A. K.; Puschmann, H. “OLEX2: A Complete Structure Solution, Refinement and Analysis Program." J. Appl. Crystallogr. 2009, $42(2), 339-341$.

[4] Sheldrick, G. M. "Crystal Structure Refinement with SHELXL." Acta Crystallogr. Sect. C Struct. Chem. 2015, 71, 3-8.

[5] Liu, Q.; Jordan, R. F. Multinuclear Palladium Olefin Polymerization Catalysts Based on SelfAssembled Zinc Phosphonate Cages. Organometallics 2018, 37 (24), 4664-4674.

[6] Willis, S. A.; Dennis, G. R.; Zheng, G.; Price, W. S. Hydrodynamic Size and Scaling Relations for Linear and 4 Arm Star PVAc Studied Using PGSE NMR. J. Mol. Liq. 2010, 156 (1), 45-51. [7] HyperChem(TM) Professional 8.0.7, Hypercube, Inc., 1115 NW 4th Street, Gainesville, Florida 32601, USA. 